\title{
Accounting for Clouds in Sea Ice Models
}

Aleksandr P. Makshtas, Edgar LAndreas,

Pa vel N. Svya shchennikov, and Valery F. Timachev
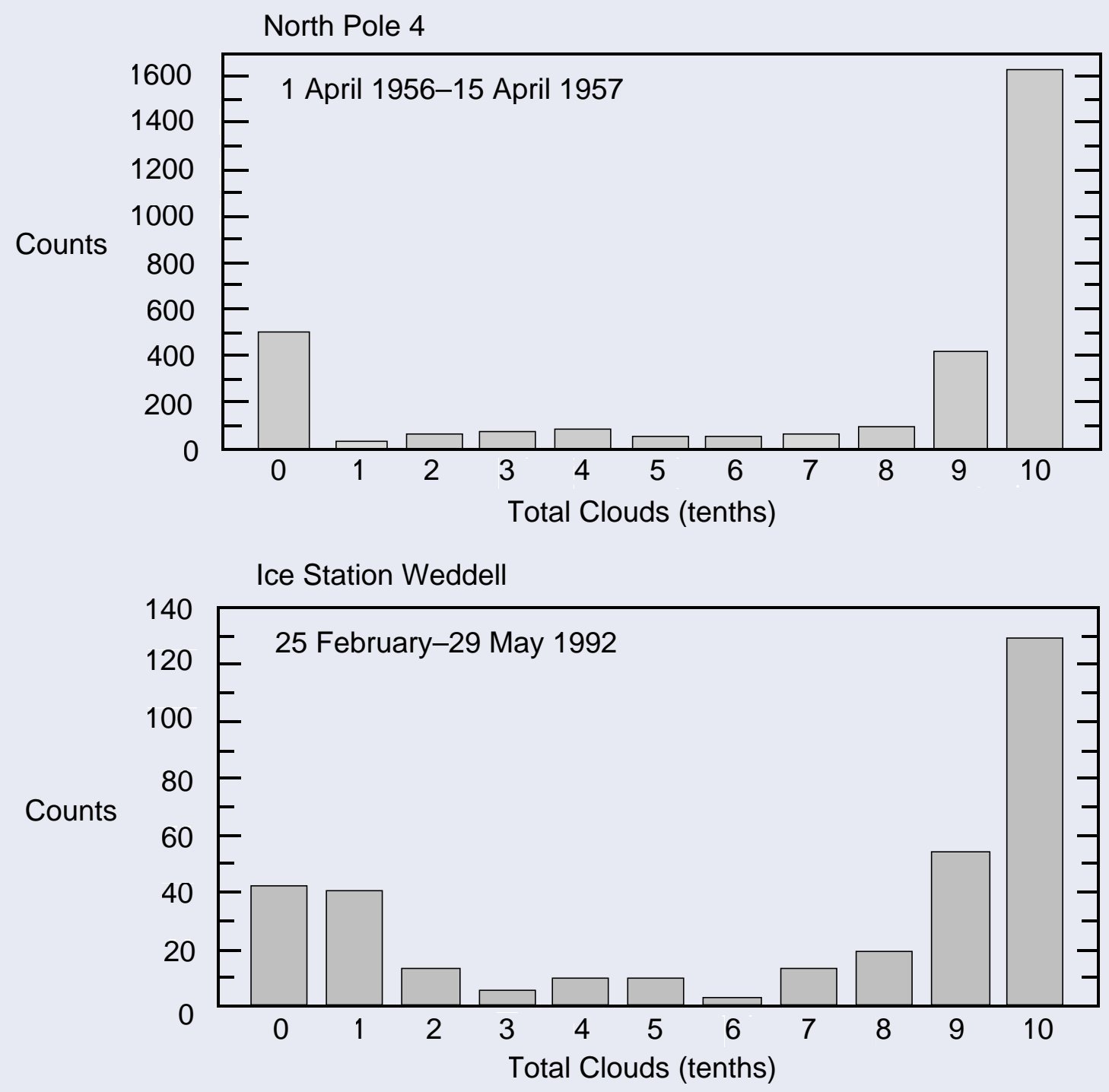
Abstract: Over sea ice in winter, the clouds, the surfacelayer air temperature, and the longwave radiation are closely coupled. This report uses archived data from the Russian North Pole (NP) drifting stations and recent data from Ice Station Weddell (ISW) to investigate this coupling. Both Arctic and Antarctic distributions of total cloud amount are U-shaped: that is, observed cloud amounts are typically either $0-2$ tenths or 8-10 tenths in the polar regions. These data obey beta distributions; roughly 70 station-years of observations from the NP stations yielded fitting parameters for each winter month. Although surface-layer air temperature and total cloud amount are correlated, it is not straightforward to predict one from the other, because temperature is normally distributed while cloud amount has a U-shaped distribution. Nevertheless, the report presents a statistical algorithm that can predict total cloud amount in winter from surface-layer temperature alone and, as required, produces a distribution of cloud amounts that is U-shaped. Because sea ice models usually need cloud data to estimate incoming longwave radiation, this algorithm may be useful for estimating cloud amounts and, thus, for computing the surface heat budget where no visual cloud observations are available but temperature is measured - from the Arctic buoy network or from automatic weather stations, for example. The incoming longwave radiation in sea ice models is generally highly parameterized. The report evaluates five common parameterizations using data from NP-25 and ISW. The formula for estimating incoming longwave radiation that König-Langlo and Augstein developed using both Arctic and Antarctic data has the best properties but does depend nonlinearly on total cloud amount. This nonlinearity is crucial since cloud distributions are U-shaped, while common sources of cloud data tabulate only mean monthly values. The report therefore closes by using a one-dimensional sea ice model to investigate how methods of averaging cloud amounts affect predicted sea ice thickness in the context of the five longwave radiation parameterizations.

Cover: Histograms of total cloud amount based on a year of observations on Russian drifting station North Pole 4 and three months of observations on Ice Station Weddell. Because both histograms are U-shaped, the computed average cloud amount, 5-7 tenths, is observed only infrequently.

\section{How to get copies of CRREL technical publications:}

Department of Defense personnel and contractors may order reports through the Defense Technical Information Center: DTIC-BR SUITE 0944 8725 J OHN J KINGMAN RD

FT BELVOIR VA 22060-6218

Telephone 18002253842

E-mail help@dtic.mil

msorders@dtic.mil

WwW http://www.dtic.mil/

All others may order reports through the National Technical Information Service: NTIS

5285 PORT ROYAL RD

SPRINGFIELD VA 22161

Telephone 17034874650

17034874639 (TDD for the hearing-impaired)

E-mail_orders@ntis.fedworld.gov

WWW http://www.fedworld.gov/ntis/ntishome.html

A complete list of all CRREL technical publications is available from

USACRREL (CECRL-IB)

72 LYME RD

HANOVER NH 03755-1290

Telephone 16036464338

E-mail techpubs@crrel.usace.army.mil

For information on all aspects of the Cold Regions Research and Engineering Laboratory, visit our World Wide Web site: http://www.crrel.us ace.army.mil 


\section{CRREL Report 98-9}

\section{Accounting for Clouds in Sea Ice Models}

Aleksandr P. Makshtas, Edgar L Andreas,

Pavel N. Svyashchennikov, and Valery F. Timachev

December 1998 


\section{PREFACE}

This report was prepared by Dr. Aleksandr P. Makshtas, Head of the Air-Sea Interaction Laboratory, Arctic and Antarctic Research Institute (AARI), St. Petersburg, Russia, Dr. Edgar L Andreas, Research Physicist, Snow and Ice Division, Research and Engineering Directorate, U.S. Army Cold Regions Research and Engineering Laboratory (CRREL), Hanover, New Hampshire, Dr. Pavel N. Svyashchennikov, Senior Reseach Scientist, and Valery F. Timachev, Senior Reseach Scientist, AARI, St. Petersburg, Russia.

The U.S. Office of Naval Research supported this research through contracts N0001496MP30005 and N0001497MP30002; the U.S. National Science Foundation supported it with grants OPP-90-24544, OPP-93-12642 and OPP-97-02025; the U.S. Department of the Army supported it with project 4A161102AT24; and the Russian Fund for Fundamental Investigations supported it through projects 96-0789159 and 97-05-65926.

The authors thank their colleagues Dr. Boris Ivanov of AARI and Kerry Claffey of CRREL for their help with sampling and analyzing the Ice Station Weddell data, and Walter Tucker and Dr. Donald Perovich of CRREL for reviewing the manuscript. The National Snow and Ice Data Center at the University of Colorado, Boulder, provided the CD-ROM containing much of the data from the Russian drifting stations used here.

The contents of this report are not to be used for advertising or promotional purposes. Citation of brand names does not constitute an official endorsement or approval of the use of such commercial products. 


\section{CONTENTS}

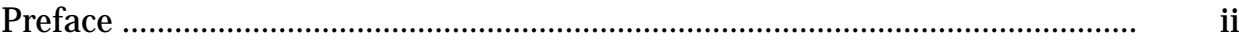

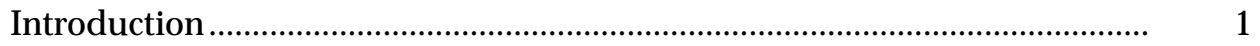

Cloud amount in the central Arctic ................................................................. 5

Estimating total cloud amount in the winter ................................................. 10

Parameterizing the longwave radiation balance in sea ice models .............. 13

Brunt's method ......................................................................................... 14

Marshunova's method ................................................................................ 14

Maykut and Church's method ………………….................................... 15

Satterlund's method ….............................................................................. 15

Kønig-Lango and Augstein's method .................................................... 15

New test of the longwave parameterizations ............................................ 16

Model sensitivity to the description of longwave radiation .......................... 18

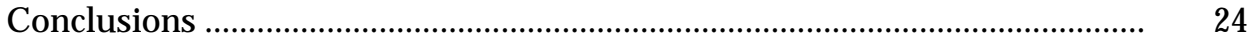

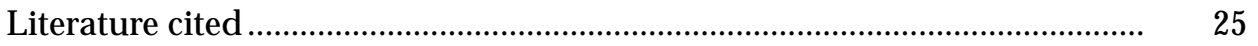

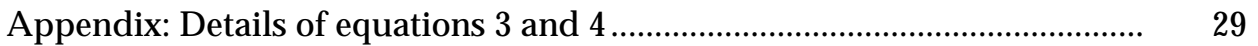

Abstract ................................................................................................. 31

\section{ILLUSTRATIONS}

Figure

1. Annual variation in monthly averaged total cloud amount over the Arctic Ocean on the basis of satellite data, visual observations on the North Pole drifting stations, and the cloud climatology published by Warren et al. (1988)

2. Annual cycle in amounts of low-level, mid-level, high-level, and total clouds and in ice crystal precipitation in the lower troposphere

3. Histogram of total cloud amount observed on North Pole 4 from 1 April 1956 to 15 April 1957

4. Histogram of total cloud amount observed during the drift of Ice Station Weddell from 25 February through 29 May 1992

5. February positions of the North Pole drifting stations manned between 1938 and 1991

6. Observations for 1955-1991 of the frequency of clear skies and overcast skies in February on the North Pole drifting stations indicated in Figure 5 
7. Frequency of clear skies and overcast skies in July on the North Pole drifting stations indicated in Figure 5

8. Observed and modeled total cloud amounts based on observations and data from North Pole 25 in November 1982.

9. Temporal variability of 240 consecutive 3-hour observations of total cloud amount in November 1982 on North Pole 25 and our modeled total cloud amount based on eq 4

10. Measured incoming longwave radiation during May 1992 on Ice Station Weddell and predictions of it using the equations of Brunt, Marshunova, Maykut and Church, Satterlund, and König-Langlo and Augstein

11. Temporal variability of total cloud amount for November 1982 on North Pole 25

12. Temporal variability of the daily averaged surface-layer air temperature and the incoming longwave radiation for November 1982 on North Pole 25

13. Temporal variability of the longwave radiation balance and the sensible heat flux for the middle 10 days in May 1992 on Ice Station Weddell

\section{TABLES}

Table

1. Percent of time with overcast and clear skies in various regions of the Russian Arctic and in the central Arctic Basin

2. Total cloud amounts observed on the North Pole drifting stations .. 6

3. Low cloud amounts observed on the North Pole drifting stations...

4. Values of $\hat{\alpha}$ and $\hat{\beta}$ for the beta distributions describing total cloud amount in the winter

5. Correlation coefficients between the total cloud amounts observed on North Pole 25 and cloud amounts estimated using eq 4 .......... 12

6. Coefficients $a_{\mathrm{M}}$ and $b_{\mathrm{M}}$ for use in eq 9

7. Monthly averages of the coefficient $c_{M}$ for use in eq 9

8. Observed and various modeled values of the longwave radiation balance and incoming longwave radiation

9. For our modeled sea ice cover, using various longwave parameterizations and the North Pole 25 data from October 1982 to October 1983, the maximum and minimum thickness, the amplitude of the annual variation in thickness, and the dates on which melting first begins in the snowpack and cooling in the sea ice begins

10. Incoming longwave radiation during the winter of 1982-1983 on North Pole 25. 


\title{
Accounting for Clouds in Sea Ice Models
}

\author{
ALEKSANDR P. MAKSHTAS, EDGAR L ANDREAS, \\ PAVEL N. SVYASHCHENNIKOV, AND VALERY F. TIMACHEV
}

\section{INTRODUCTION}

Clouds play a dominant role in determining shortwave and longwave radiation transfer in the atmosphere. Cloud area, height, thickness, and water content, among other properties, all influence the radiative fluxes (Curry and Ebert 1990). For sea ice modeling in polar regions, having an adequate description of the cloud cover is especially important for estimating the radiative fluxes at the snow or sea ice surface, because surface melting and ice growth are quite sensitive to shortwave and longwave radiation (Maykut and Untersteiner 1971, Curry and Ebert 1990). In turn, the phase changes and heat storage in the snow or ice cover set the intensity of the surface turbulent and radiative fluxes and the conductive flux into the ice (Makshtas 1991a). As a result, there is a strong climatic feedback between the sea ice and the albedo in polar regions (Barry 1984).

Despite the intensive development of methods for remotely sensing the atmosphere, the main source of data on the climatic characteristics of Arctic cloudiness is still in-situ visual observations. Though polar-orbiting satellites frequently cross the Arctic, the small image contrast between the ice cover and the clouds in the visible in summer and in the infrared in winter makes using satellite information difficult for estimating cloudiness in polar regions, as Raschke (1987) explains. Figure 1 illustrates this problem. It shows cloud amounts deduced from satellite

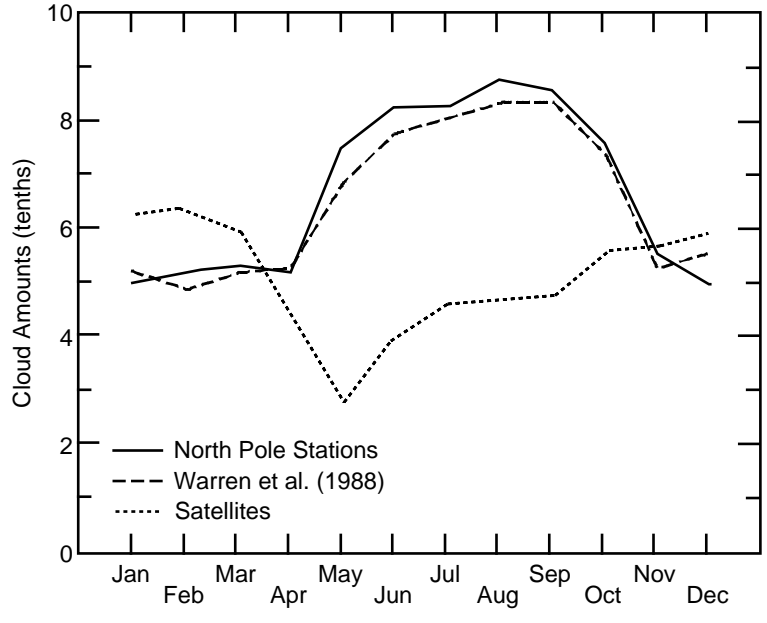

Figure 1. Annual variation in monthly averaged total cloud amount over the Arctic Ocean on the basis of satellite data, visual observations on the North Pole drifting stations, and the cloud climatology published by Warren et al. (1988). The satellite and Warren et al. traces derive only from grid points north of $80^{\circ} \mathrm{N}$. (Adapted from Moritz et al. 1993.) 
data, surface-based visual observations summarized in a climatic atlas (Warren et al. 1988), and visual observations on the Russian North Pole (NP) drifting stations. The figure suggests that, compared to visual observations, the satellite data overestimate the mean monthly cloud amount in the winter and underestimate it in the summer.

In the last few years, several works have attempted to evaluate the influence of ice crystals (Curry and Ebert 1992, Overland and Guest 1991) and Arctic haze (Blanchet 1989, Zachek 1996) on the radiation and thermal state of the Arctic atmosphere and the surface. For example, Curry and Ebert (1992), building on Huschke's (1969) cloud statistics, estimate the annual variation of total cloud amount by including the effects of low, medium, and high-level clouds and lower tropospheric ice crystal precipitation (Fig. 2). They evaluate the role and quantity of ice crystal precipitation by comparing the results of calculations from numerical radiation models that do not incorporate ice crystal precipitation with measurements of the longwave radiation balance or the incoming longwave radiation. Overland and Guest (1991) also note a discrepancy between observations and model calculations of incoming longwave radiation and likewise suggest that the missing modeled downward longwave radiation might be explained by ice crystal precipitation, "diamond dust." They did not, however, rule out other explanations such as blowing snow or optically thin clouds. Alternatively, on comparing incoming longwave radiation measurements with theoretical estimates of the effective radiant emittance of the atmosphere, Zachek (1996) shows that the temporal variability of this radiation is closely connected with the temporal variability of the concentration of atmospheric aerosols, especially in February-May, when this concentration has its maximum.

Although it is important to continue research on the above-cited phenomena and to develop methods to account for these in calculations of incoming longwave radiation with atmospheric radiation models, here we will consider the simpler and more conventional characteristics of cloudiness observable visually during standard meteorological observations. These are total $(n)$ and low $\left(n_{\mathrm{L}}\right)$ cloud amount, the cloud parameters most frequently used in climate research for calculating the radiative fluxes.

The atlases of Gorshkov (1983) and Prik (1965), among many others, give the spatial and temporal variability of several climatic variables in the Arctic Basin based on generalized data from polar land stations and Russian drifting stations

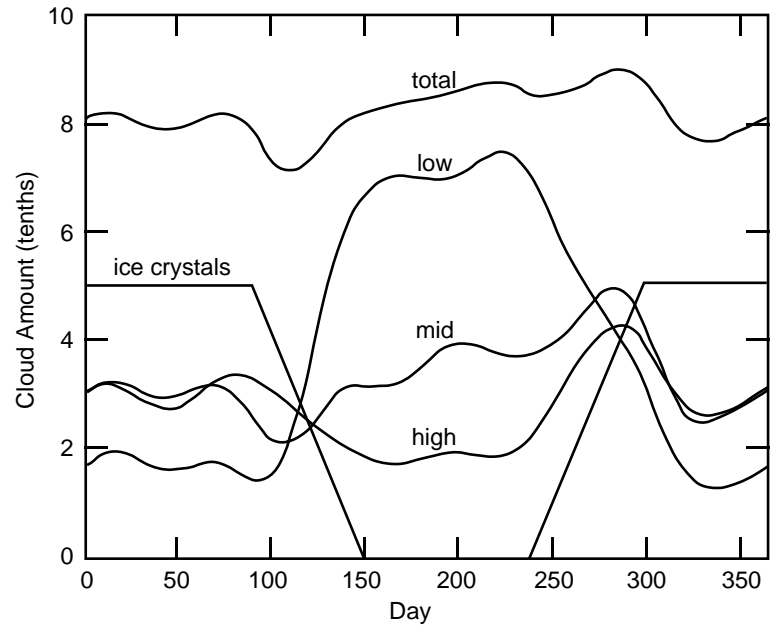

Figure 2. Annual cycle in amounts of low-level, midlevel, high-level, and total clouds and in ice crystal precipitation in the lower troposphere. (Adapted from Curry and Ebert 1992.) 
through NP-7. These climatic data, which include charts and tables of monthly and yearly averages of the spatial and temporal distributions of $n$ and $n_{\mathrm{L}}$, are still the basis for describing radiative energy exchange in climatic and prognostic models of Arctic sea ice (e.g., Parkinson and Washington 1979, Hibler 1979, Ebert and Curry 1993).

The creation of a complete and corrected archive of the standard meteorological data collected on the Russian North Pole drifting stations within the framework of the Russian-American data rescue project, however, now provides the opportunity for a more accurate description of cloudiness and its temporal variability in the central Arctic. The National Snow and Ice Data Center (NSIDC 1996) at the University of Colorado in Boulder recently issued a compact disk containing these data, Arctic Ocean Snow and Meteorological Observations from Drifting Stations: 1937, 1950-1991, Version 1.0.

Using this large mass of recently available data, we have confirmed Voskresenskii and Bryazgin's (1988) conclusion that, in the central part of the Arctic Basin, cloud amount tends to fall in two ranges $0-2$ tenths and 8-10 tenths. In other words, the frequency distribution of cloud amount in the winter in the Arctic is U-shaped. Our more limited analyses of cloud observations in the Arctic during one year at NP-4 (Fig. 3) and in the Antarctic during three months on Ice Station Weddell (Fig. 4) show the same bimodal distribution. Such histograms can be described with the beta distribution (Harr 1977). Clearly, the common practice of quantifying cloud amount with only its average value is, at least for spatial scales less than a thousand kilometers, not correct: For typical cloud distributions over sea ice, the mean value is the least likely value.

Our investigation of the correlation between atmospheric surface-layer temperature and total cloud amount, based on the NSIDC data, has allowed us to develop a method for partially reconstructing total cloud amount in winter using only air temperature data. Conveniently, temperature is the most readily available meteorological parameter; for example, the Arctic buoy network yields it routinely for much of the Arctic. This method appears to be potentially useful

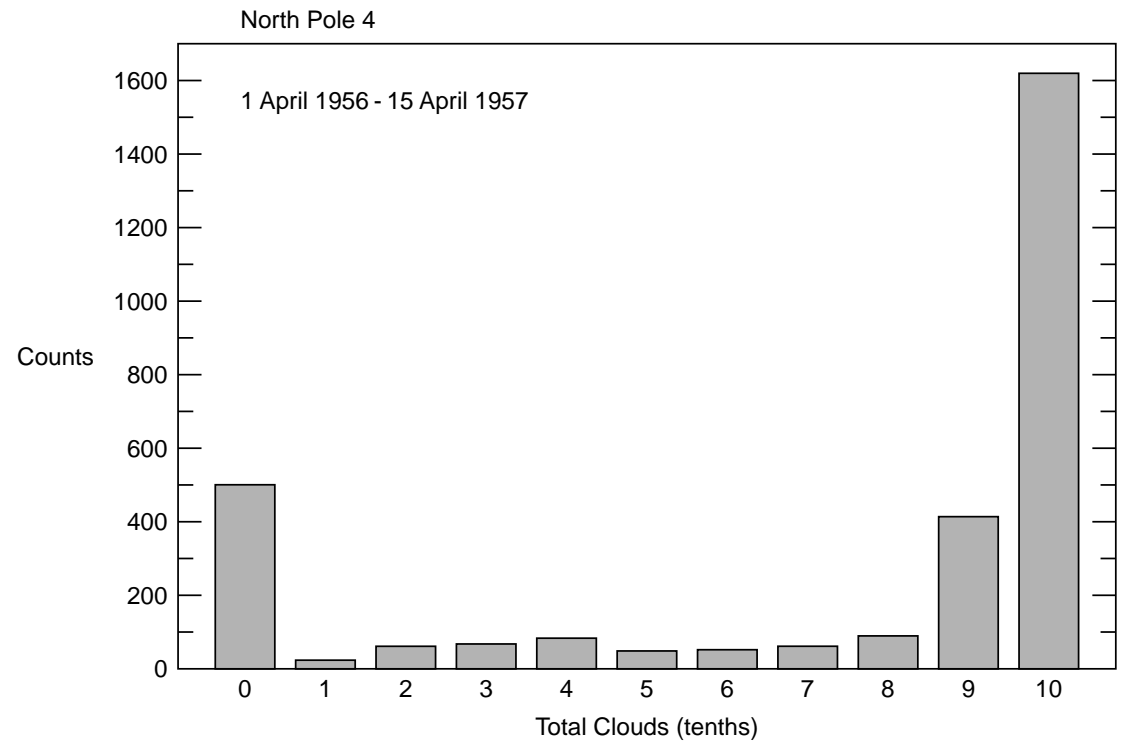

Figure 3. Histogram of total cloud amount observed on North Pole 4 from 1 April 1956 to 15 April 1957. 


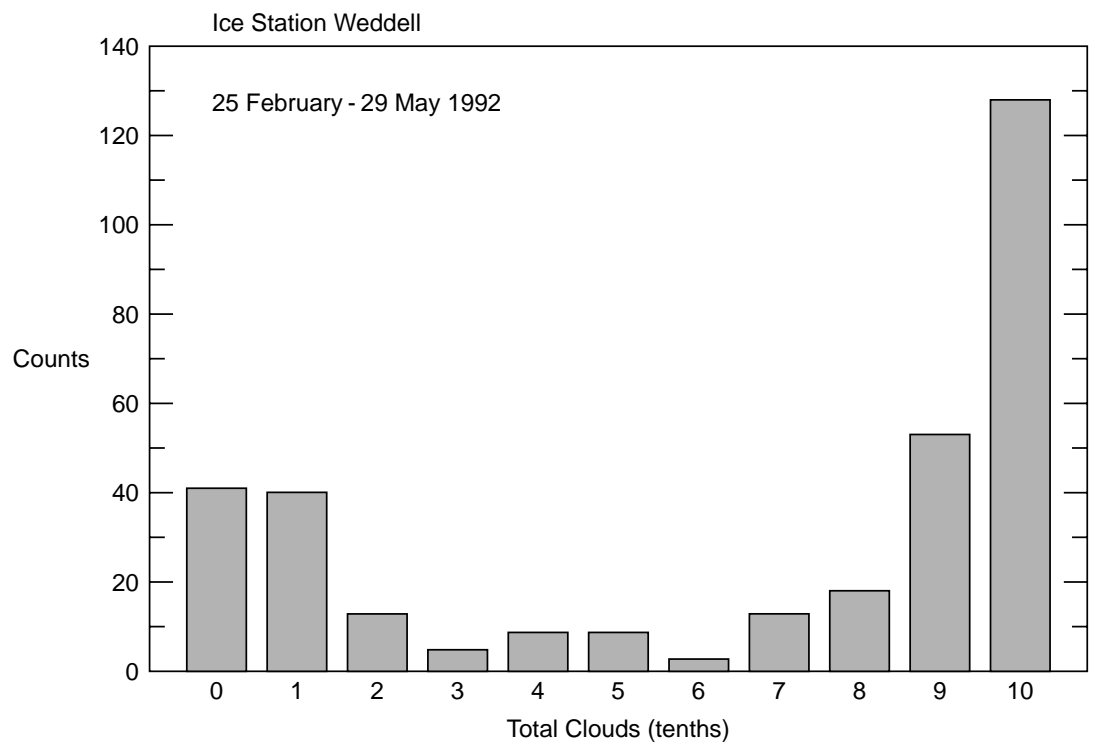

Figure 4. Histogram of total cloud amount observed during the drift of Ice Station Weddell from 25 February through 29 May 1992.

for remote sensing and numerical modeling, especially when cloud amount is an external parameter of the model.

Another no less important problem in developing climatic sea ice models and using them for numerical experiments is adequately accounting for cloud amount in calculations of shortwave and longwave radiation (Curry and Ebert 1990, Doronin and Kheisin 1975). About 10 empirical formulas exist for estimating incoming longwave radiation from measured surface-layer temperature, characteristics of the clouds (i.e., amount and type of clouds), and, sometimes, surfacelayer humidity. Recently, König-Langlo and Augstein (1994) and Key et al. (1996) reviewed some of these parameterizations and evaluated their accuracy in accounting for incoming longwave radiation in polar regions. The meteorological data they used for their evaluations came from Resolute (Canada), Barrow (Alaska), NyÅlesund (Spitzbergen), and Georg von Neumayer Station in Antarctica.

Here we consider additional data collected on the Russian-American drifting station Weddell-1 (or Ice Station Weddell, ISW) when that station drifted through the western Weddell Sea in 1992 (Andreas et al. 1992). On ISW, we used both Russian and American instruments to measure the hourly averaged components of the radiation budget during the Antarctic fall and winter (February through May) (Claffey et al. 1995). In the second part of this report, we compare the incoming longwave radiation data collected on ISW with the most frequently used parameterizations for incoming longwave radiation.

Obviously, one of the major applications for a parameterization of incoming longwave radiation is for estimating that component of the surface heat budget in models of sea ice in polar regions. Therefore, we report a number of numerical experiments done with a quasi-stationary, zero-dimensional thermodynamic sea ice model similar to Semtner's (1976). Our purpose is to study the influence of various methods for describing meteorological information and various parameterizations for the longwave radiation balance on the equilibrium thickness of sea ice in the Arctic. 


\section{CLOUD AMOUNT IN THE CENTRAL ARCTIC}

Prik (1965) and Voskresenskii and Bryazgin (1988) published comparatively complete data on the characteristics of cloudiness in the north polar region. On generalizing data from Russian polar stations and drifting stations through NP-14, Voskresenskii and Bryazgin found marked spatial nonhomogeneity in the frequency distribution of clear and overcast skies (Table 1).

Table 1 shows that, in winter, overcast skies occur most frequently in the eastern and western regions of the Russian Arctic coast, probably because of the prevalence of moist air masses originating over the Atlantic and Pacific Oceans. In the central region of the Russian Arctic coast and in the eastern part of the Arctic Basin, where the observations in Table 1 rely heavily on data from the NP drifting stations, anticyclonic circulation is more common. As a result and also because these regions are more distant from sources of moist air, periods with clear skies are roughly twice as likely in winter than along the eastern and western coasts.

In summer, significant uniformity characterizes cloud amount in the Arctic. Overcast skies occur roughly $80 \%$ of the time in all regions and perhaps even more frequently in the central basin.

Table 1. Percent of the time with overcast (8-10 tenths) and clear ( $0-2$ tenths) skies in various regions of the Russian Arctic and in the central Arctic Basin (from Voskresenskii and Bryazgin 1988).

\begin{tabular}{|c|c|c|c|c|}
\hline & \multicolumn{2}{|c|}{ Summer } & \multicolumn{2}{|c|}{ Winter } \\
\hline & $0-2$ tenths & $8-10$ tenths & $0-2$ tenths & $8-10$ tenths \\
\hline Western Coast & 13 & 76 & 29 & 60 \\
\hline Central Coast & 11 & 80 & 44 & 44 \\
\hline Eastern Coast & 13 & 70 & 16 & 56 \\
\hline Central Basin & 7 & 88 & 40 & 49 \\
\hline
\end{tabular}

The opportunity for a more complete analysis of the temporal and spatial variability of cloudiness in the central Arctic is now, however, available with the creation of the CD-ROM archiving the standard meteorological observations from all the Russian North Pole drifting stations (NSIDC 1996). For this purpose, we have generated, for each drifting station, time series consisting of either 3-hour or 6-hour observations for each month of the station's drift. In other words, for each month we have about 70 time series, spanning 1938 to 1991, that describe intermonth and interannual variability of total and low cloud amount in the central Arctic. To complement the analysis in Table 1, we averaged these data and present in Tables 2 and 3 the resulting statistics of total and low cloud amount at the drifting stations.

As in Table 1, the statistics in Tables 2 and 3 indicate a basic difference between the modes of total and low cloud amount in winter and summer. In the winter (November to April), there are two practically equal maxima in the distributions of total cloud amount, one for 0-2 tenths and a second for 9-10 tenths. The U-shaped form of the frequency distribution is thus quite obvious. Also in winter, cloud amounts in the 3- to 8-tenths bins have a comparatively consistent distribution. Lastly, on comparing the winter total and low cloud amounts in Tables 2 and 3 , respectively, we see a prevalence of middle and upper level clouds in winter. 
Table 2. Total cloud amounts ( $n$, in percent) observed on the North Pole drifting stations.

\begin{tabular}{|c|c|c|c|c|c|c|c|c|c|c|}
\hline & \multicolumn{10}{|c|}{ Total cloud amount in tenths } \\
\hline & \multicolumn{2}{|c|}{$0-2$} & \multicolumn{2}{|c|}{$3-4$} & \multicolumn{2}{|c|}{ 5-6 } & \multicolumn{2}{|c|}{$7-8$} & \multicolumn{2}{|c|}{$9-10$} \\
\hline & Mean $^{*}$ & $S t d$ & Mean & $S t d$ & Mean & $\overline{S t d}$ & Mean & $S t d$ & Mean & Std \\
\hline Jan & 40 & 15 & 9 & 8 & 5 & 4 & 6 & 5 & 39 & 12 \\
\hline Feb & 37 & 15 & 11 & 8 & 5 & 4 & 7 & 4 & 40 & 13 \\
\hline March & 35 & 16 & 12 & 7 & 6 & 4 & 8 & 5 & 40 & 13 \\
\hline April & 34 & 13 & 10 & 7 & 5 & 3 & 7 & 4 & 43 & 13 \\
\hline May & 17 & 8 & 4 & 3 & 3 & 2 & 5 & 2 & 71 & 9 \\
\hline June & 8 & 7 & 3 & 2 & 2 & 2 & 5 & 3 & 82 & 11 \\
\hline July & 6 & 5 & 3 & 2 & 2 & 2 & 5 & 3 & 84 & 9 \\
\hline Aug & 4 & 4 & 2 & 2 & 1 & 1 & 4 & 3 & 88 & 8 \\
\hline Sept & 6 & 4 & 4 & 2 & 2 & 2 & 4 & 3 & 84 & 7 \\
\hline Oct & 13 & 9 & 6 & 4 & 4 & 3 & 7 & 4 & 70 & 10 \\
\hline Nov & 33 & 15 & 9 & 6 & 5 & 5 & 7 & 5 & 46 & 16 \\
\hline Dec & 38 & 14 & 9 & 8 & 5 & 4 & 6 & 5 & 41 & 12 \\
\hline
\end{tabular}

* "Mean" is the average percentage of the observations in the listed category; "Std" is the standard deviation of the data in that category.

Table 3. Low cloud amounts ( $n_{L}$, in percent) observed on the North Pole drifting stations.

\begin{tabular}{|c|c|c|c|c|c|c|c|c|c|c|}
\hline & \multicolumn{10}{|c|}{ d amount in tenths } \\
\hline & \multicolumn{2}{|c|}{$0-2$} & \multicolumn{2}{|c|}{$3-4$} & \multicolumn{2}{|c|}{$5-6$} & \multicolumn{2}{|c|}{$7-8$} & \multicolumn{2}{|c|}{$9-10$} \\
\hline & Mean $^{*}$ & $S t d$ & Mean & $S t d$ & Mean & $S t d$ & Mean & $S t d$ & Mean & Std \\
\hline Jan & 77 & 12 & 1 & 2 & 1 & 2 & 1 & 2 & 18 & 11 \\
\hline Feb & 78 & 14 & 1 & 2 & 1 & 2 & 1 & 2 & 16 & 11 \\
\hline March & 80 & 12 & 2 & 2 & 2 & 2 & 1 & 1 & 13 & 10 \\
\hline April & 78 & 14 & 2 & 2 & 1 & 2 & 1 & 2 & 16 & 12 \\
\hline May & 38 & 11 & 1 & 1 & 2 & 1 & 2 & 2 & 54 & 11 \\
\hline June & 22 & 11 & 2 & 2 & 2 & 2 & 3 & 2 & 68 & 12 \\
\hline July & 21 & 12 & 2 & 1 & 2 & 2 & 3 & 2 & 69 & 13 \\
\hline Aug & 18 & 10 & 2 & 1 & 2 & 2 & 3 & 2 & 73 & 11 \\
\hline Sept & 26 & 11 & 2 & 2 & 2 & 2 & 3 & 2 & 65 & 12 \\
\hline Oct & 45 & 13 & 2 & 2 & 3 & 2 & 3 & 2 & 45 & 13 \\
\hline Nov & 68 & 16 & 2 & 3 & 2 & 2 & 1 & 2 & 24 & 13 \\
\hline Dec & 76 & 13 & 1 & 2 & 1 & 1 & 1 & 1 & 19 & 11 \\
\hline
\end{tabular}

* "Mean" is the average percentage of the observations in the listed category; "Std" is the standard deviation of the data in that category.

In summer (June to September), overcast skies dominate, there are very few occurrences of skies with 3-8 tenths cloud cover, and low clouds constitute most of the cover. This latter observation is likely a consequence of the cold, wet, and practically isothermal surface (melting snow on sea ice). May and October are short transition seasons between the winter and summer cloud distributions.

Next, we use the observations from the drifting stations to consider the interannual variability of cloud amount in the central Arctic. One feature of the drifting stations necessary to consider in this analysis, however, is that they constantly changed position. Although this drifting allowed them to sample wide areas of the Arctic, we worry that their observational time series might not be homogeneous as a result. Fortunately, we can check for homogeneity. Usually, two or three drifting stations worked in the Arctic simultaneously. By computing correlation coefficients for 3-hour and daily averaged meteorological data obtained 


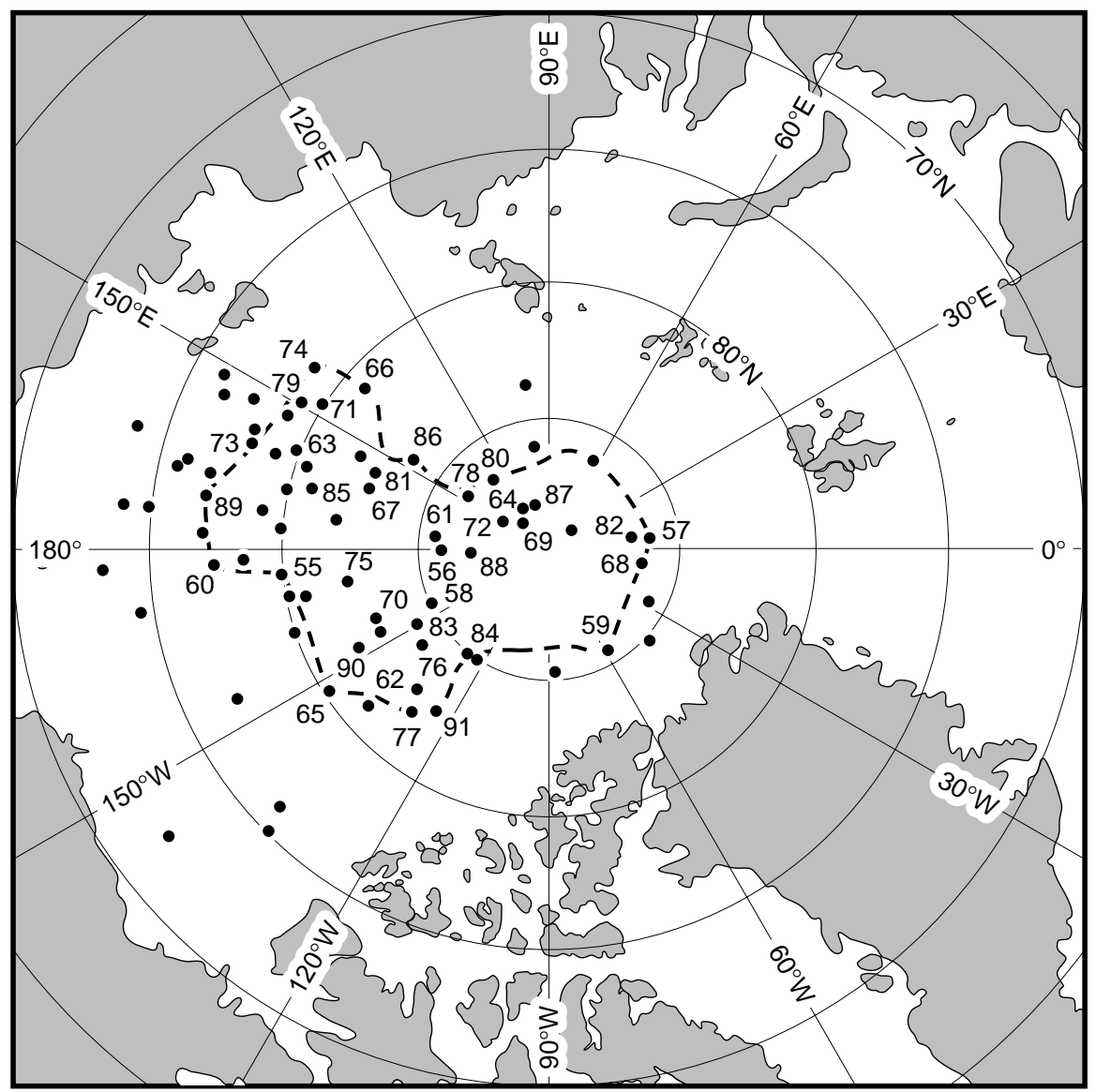

Figure 5. February positions of the North Pole drifting stations manned between 1938 and 1991. The dashed line encloses the region under study here. The numbers denote stations that contributed each year's data for our 1955-1991 analyses.

at the same time on different stations, we found significant correlations between stations located in different regions. This seems reasonable in light of the obvious uniformity of the surface and the distance the central basin is from continents and oceans, where advection can foster inhomogeneity (Table 1).

In effect, we could thus assume that all stations in the central Arctic at the same time were sampling the same cloud distribution. We thus created a time series of cloud observations covering 1955-1991. But to keep the time series homogeneous, we considered data from only one station above $77^{\circ} \mathrm{N}$ each year. We use this series for evaluating trends and making a more correct analysis of cloud characteristics in the Arctic. Figure 5 shows the area on which we focus our analysis, the February position of all the NP stations, and the locations of the stations that yielded the data year we used in our analyses. The figure confirms that the stations providing our data were randomly distributed around the central Arctic.

As we explained above, total cloud amount and, to a smaller degree, low cloud amount have U-shaped distributions, unlike air temperature, which has a normal distribution. This means that it is incorrect to describe the characteristics of a time series of total or low cloud amount with the arithmetic average, as was done, for example, in the Gorshkov (1983) atlas. On the basis of Tables 2 and 3, it also seems appropriate to describe the spatial and temporal variability of Arctic cloudiness 

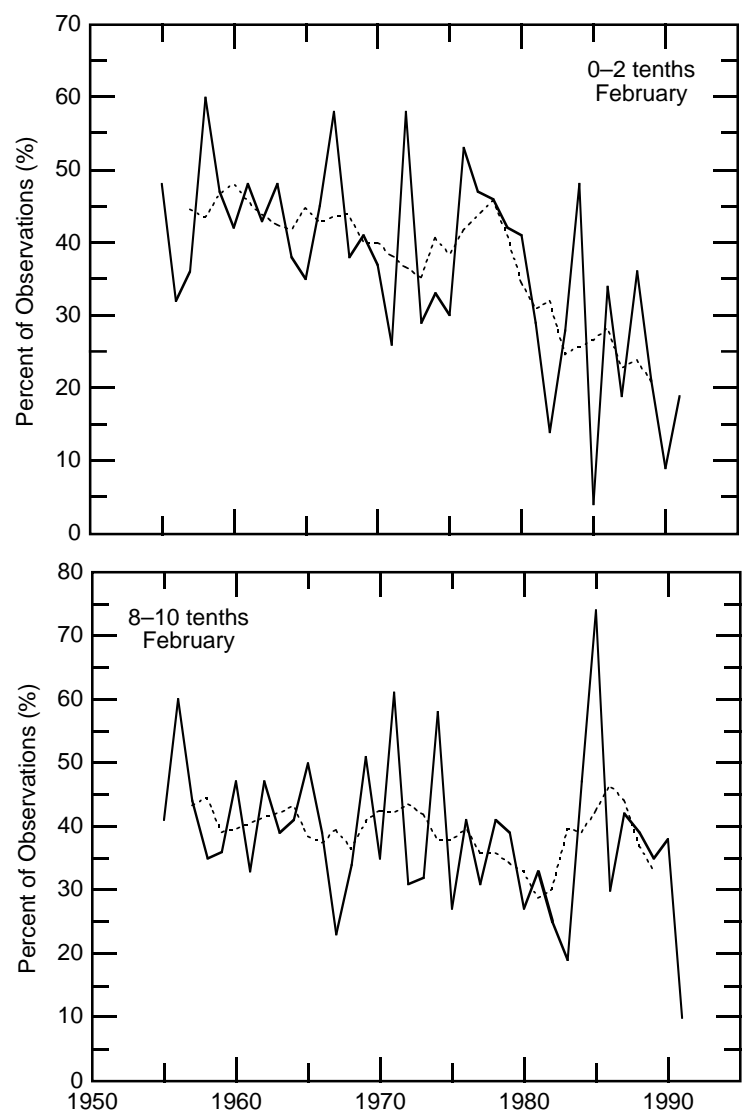

Figure 6. Observations for 1955-1991 of the frequency of clear skies (0-2 tenths) and overcast skies (8-10 tenths) in February on the North Pole drifting stations indicated in Figure 5. The dashed curves show the 5-year running means.

just in terms of the frequency of clear (0-2 tenths) and overcast (8-10 tenths) skies. Using these criteria, we find an appreciable reduction in the frequency of clear skies in winter (namely, February) between 1955 and 1991 but no significant change in the frequency of overcast skies (Fig. 6). These observations imply an increase in cloud amount in winter that is probably connected with the increase in aerosol pollution in the Arctic atmosphere. After all, the concentration of aerosol pollutants peaks in the late winter and early spring (Shaw 1995). The increased aerosol concentration simply provides more cloud condensation nuclei.

Figure 7 shows time series of summer (namely, July) cloud observations and global solar radiation, the latter coming from Marshunova and Mishin (1994). We see here a reduction in the frequency of overcast skies in summer that is confirmed by a corresponding increase in the global solar radiation measured on the same drifting stations. These changes are probably related to changes in the mode of the atmospheric circulation in the Arctic. On analyzing fluctuations in the Arctic atmospheric circulation since 1963, Dmitriev (1994) documents a reduction in the frequency of latitudinal air exchange and an increase in the frequency of zonal processes. In other words, in recent years, fewer warm, moist air masses have been entering the Arctic Basin, and, as a consequence, fewer clouds have been forming in situ. 

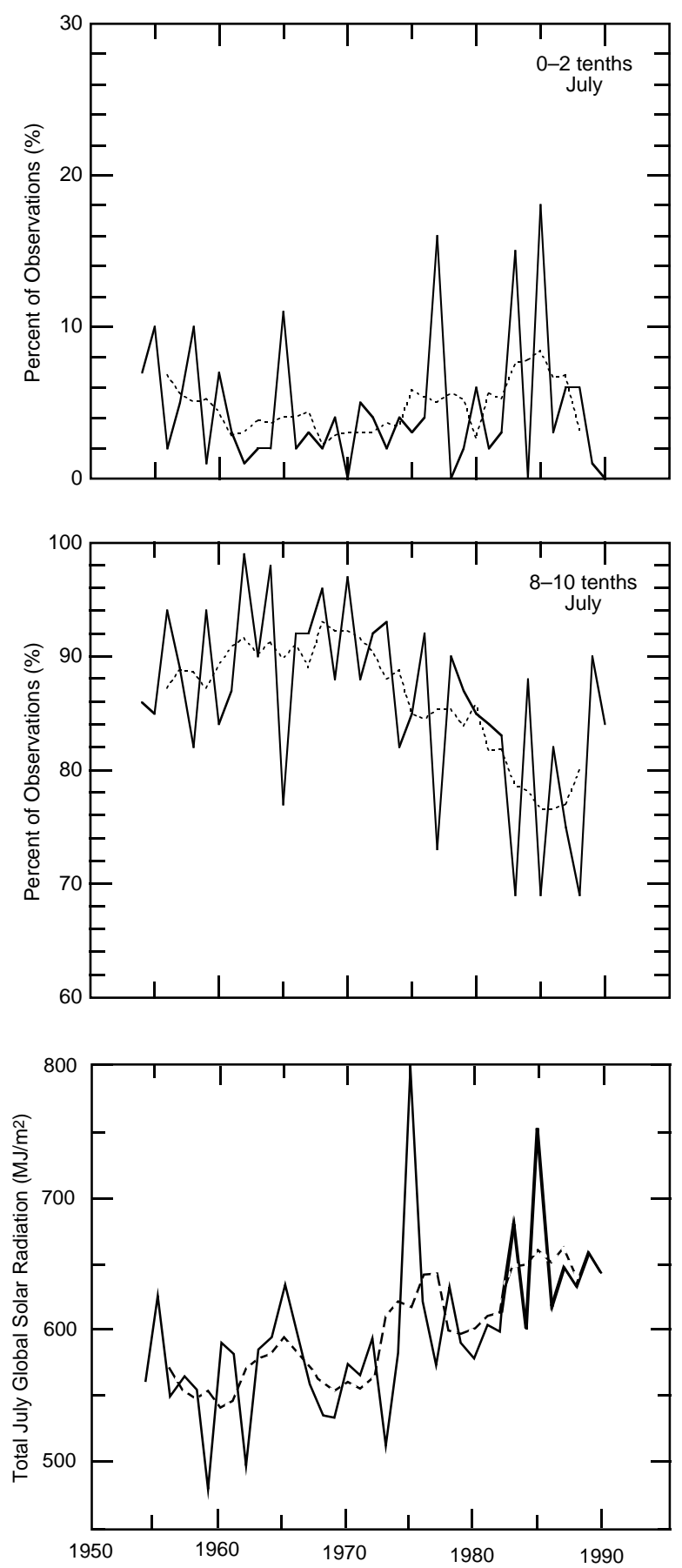

Figure 7. Frequency of clear skies (0-2 tenths) and overcast skies (8-10 tenths) in July on the North Pole drifting stations indicated in Figure 5. The total July global solar radiation on the same drifting stations comes from Marshunova and Mishin (1994). The dashed lines are 5-year running means. 


\section{ESTIMATING TOTAL CLOUD AMOUNT IN THE WINTER}

Although the spatial and temporal variability of Arctic clouds are some of the poorest documented parameters required for modeling the polar atmosphere and sea ice cover, numerical experiments with atmospheric general circulation models show that these models have the highest sensitivity to just these parameters (e.g., Cess et al. 1989). To improve and validate regional sea ice models and atmospheric general circulation models, it is therefore crucially important to develop an adequate description of cloud parameters and their spatial and temporal variability.

One possible way to increase the reliability of cloud descriptions is a method of statistical modeling that we have developed based on a correlation analysis using surface-layer air temperature $(T)$ and total cloud amount during the winter. Our analyses of archival data from the North Pole drifting stations show that the correlation coefficients between $T$ and total cloud amount $(n)$ and between $T$ and low cloud amount $\left(n_{\mathrm{L}}\right)$ for observations from November to March are, on average, 0.6 with a significance level of 0.1 in the central Arctic.

It should be noted that, because on the drifting stations there were 4- 8 observations per day, proximate observations may be correlated. That is, all the paired temperature and cloud observations may not be independent. To test whether this inherent correlation affected our analysis, we repeated the correlation analysis twice, first using only one observation per day and then using one observation every five days. These analyses, however, yielded the same correlation coefficient that we gave above.

We also calculated the correlation coefficients between air temperature and cloud amounts in time series for individual months from November to March. Again, the correlation coefficients, on average, exceed 0.6. For October data, we also found

significant correlation between temperature and cloud amounts, but the correlation was a little lower.

Based on the significant correlation between $T$ and $n$ and between $T$ and $n_{\mathrm{L}}$, it might seem possible to use a linear equation to estimate 3-hour cloud amounts from 3-hour temperature data. Such a method, however, is not justified since temperature is nearly normally distributed while cloud amount has a U-shaped distribution. Quite simply, if a random variable is normally distributed (in this case, air temperature), any new random variable obtained from it with a linear transformation (presumably the cloud amount) will also be normally distributed. Thus, because we require that any predicted time series of $n$ or $n_{\mathrm{L}}$ have a U-shaped distribution, we cannot use standard statistical modeling methods to exploit the observed high correlation between $T$ and $n$ and between $T$ and $n_{\mathrm{L}}$ but must, instead, use a more complicated statistical algorithm.

For predicting cloud amounts using air temperature data, we begin with the explicit form of the frequency distribution of total cloud amount in the Arctic Basin. This is U-shaped; we fit it with a beta distribution. The probability density function of a beta distribution, $f(x)$, for random variable $x$ in the interval $[0,1]$ is (e.g., Harr 1977, Aivazyan et al. 1983)

$$
\begin{aligned}
f(x) & =\frac{\Gamma(\alpha+\beta)}{\Gamma(\alpha) \Gamma(\beta)} x^{\alpha-1}(1-x)^{\beta-1} & & \text { for } 0 \leq x \leq 1, \\
& =0 & & \text { otherwise, }
\end{aligned}
$$

where $\Gamma$ is the gamma function. 
Empirical values of the parameters $\alpha$ and $\beta$ in eq 1 can be evaluated from the sample mean of $x, \bar{x}$, and the sample standard deviation, $s$ :

$$
\begin{aligned}
& \hat{\alpha}=\bar{x}\left(\frac{\bar{x}(1-\bar{x})}{s^{2}}-1\right), \\
& \hat{\beta}=(1-\bar{x})\left(\frac{\bar{x}(1-\bar{x})}{s^{2}}-1\right) .
\end{aligned}
$$

Table 4 shows average values of the $\hat{\alpha}$ and $\hat{\beta}$ parameters for winter calculated from eq 2 using the monthly 3-hour series of total cloud amount described above. In other words, in preparing Table 4, we had about 70 months of data to use in computing each month's average $\hat{\alpha}$ and $\hat{\beta}$ values. We did, however, exclude approximately 10 monthly values from each set of calculations, either because the correlation between $T$ and $n$ was weak or because the cloud distribution was not obviously U-shaped.

Table 4. Values of $\hat{\alpha}$ and $\hat{\beta}$ for the beta distributions describing

\begin{tabular}{|c|c|c|c|c|c|c|c|c|c|c|}
\hline & \multicolumn{2}{|c|}{ November } & \multicolumn{2}{|c|}{ December } & \multicolumn{2}{|c|}{ January } & \multicolumn{2}{|c|}{ February } & \multicolumn{2}{|c|}{ March } \\
\hline & Mean $^{*}$ & $S t d$ & Mean & $S t d$ & Mean & $S t d$ & Mean & $S t d$ & Mean & Std \\
\hline$\hat{\alpha}$ & 0.24 & 0.18 & 0.18 & 0.16 & 0.19 & 0.18 & 0.23 & 0.18 & 0.31 & 0.21 \\
\hline$\hat{\beta}$ & 0.17 & 0.11 & 0.17 & 0.13 & 0.19 & 0.15 & 0.22 & 0.15 & 0.25 & 0.16 \\
\hline
\end{tabular}
total cloud amount in the winter.

* "Mean" is the value averaged from roughly 70 months of fitted beta distributions; "Std" is the standard deviation of the values used to create the means.

Our method for statistically modeling cloud amount compatible with a beta distribution goes as follows. Let $\tilde{T}$ be the normalized surface-layer temperature. As such, $\tilde{T}$ is a random variable that is approximately normally distributed with mean 0 and standard deviation 1 . On assuming that the total cloud amount $n(\tilde{T})$ is a monotonic function of $\tilde{T}$, we know from mathematical statistics that the following expression relates $n$ to $\tilde{T}$ (Ventcel 1964, p. 263 ff.):

$$
n(\tilde{T})=\Phi_{2}^{-1}\left[\Phi_{1}(\tilde{T})\right]
$$

where $\Phi_{1}(\tilde{T})$ is the cumulative probability density function of random variable $\tilde{T}, \Phi_{2}(n)$ is the cumulative probability density function of random variable $n$, and $\Phi_{2}^{-1}(n)$ is the inverse function of $\Phi_{2}(n)$.

Since $\Phi_{2}(n)$ describes a beta distribution, eq 3 can be approximated as (Aivazyan et al. 1983):

$$
n(\tilde{T}) \cong \frac{\hat{\alpha}}{\hat{\alpha}+\hat{\beta} \exp [2 w(\tilde{T})]},
$$

where $\hat{\alpha}$ and $\hat{\beta}$ are the parameters of the beta distribution given in Table 4 , and $w(\tilde{T})$ is a function of the normalized air temperature. Appendix A fills in the mathematics on which eq 3 and 4 are based and gives the functional form for $w(\tilde{T})$. In 
summary, eq 4 yields good results for small values of $\hat{\alpha}$ and $\hat{\beta}$ but leads to significant errors if either one of them is 0.5 or more.

We tried this algorithm for predicting total cloud amount using the standard meteorological data obtained on drifting station North Pole 25, which was above $85^{\circ} \mathrm{N}$ from October 1982 to October 1983. Table 5 lists our results for the winter of 1982-1983, November through March. In the table, all the correlation coefficients have a significance level below 0.13 . In other words, based on the calculations summarized in Table 5, the probability that eq 4 is a useful model for cloud amount in winter is better than $87 \%$.

Figures 8 and 9 show other tests of our algorithm for estimating total cloud amount using data from NP-25. Figure 8 shows histograms of the observed and modeled total cloud amounts based on data collected on NP-25 in November 1982. Figure 9 compiles 240 consecutive observations of total cloud amount and our simultaneous estimates of total cloud amount based on eq 4 . The figures show that, using the $\hat{\alpha}$ and $\hat{\beta}$ coefficients averaged from all data between 1955 and 1991 and having observations of surfacelayer temperature on NP-25, we have managed to capture with eq 4 not only the U-shaped frequency distribution in total cloud amount but also, to an extent, its temporal variability.

Table 5. Correlation coefficients between the total cloud amounts observed on North Pole 25 and cloud amounts estimated using eq 4.

\begin{tabular}{ccccc} 
November & December & January & February & March \\
\hline 0.54 & 0.31 & 0.57 & 0.42 & 0.57 \\
\hline
\end{tabular}
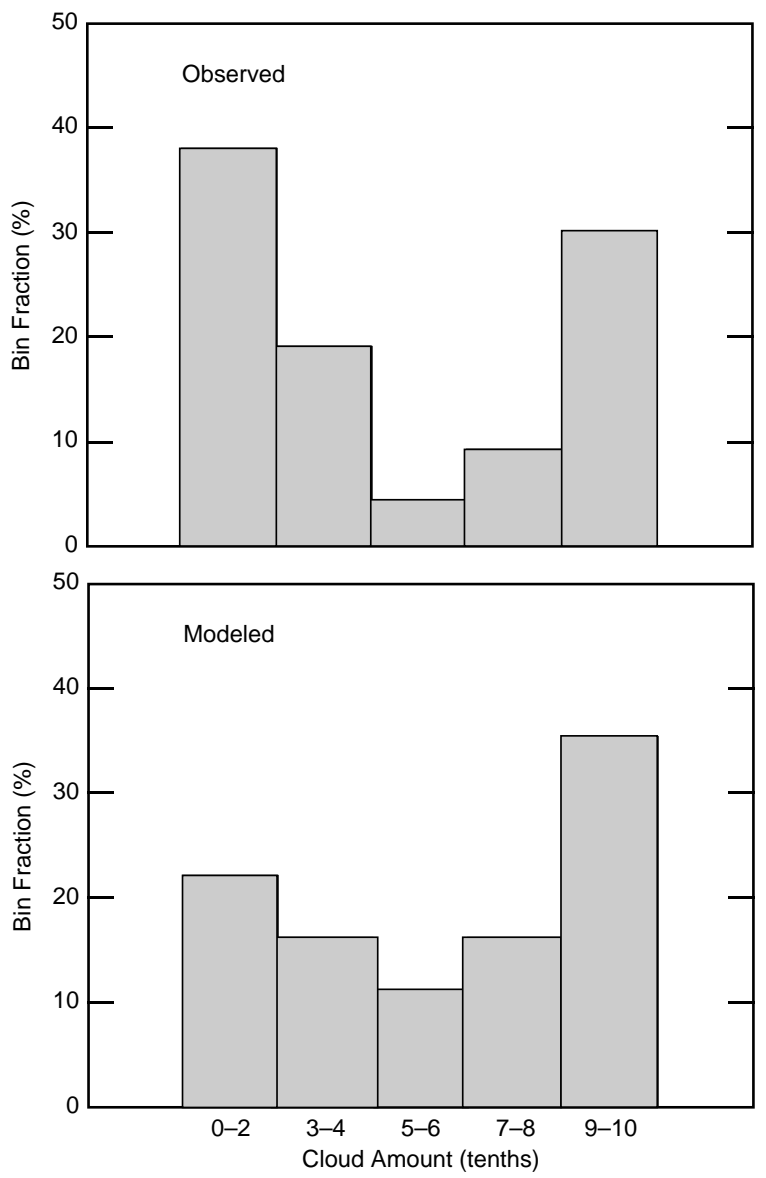

Figure 8. Observed and modeled (using eq 4) total cloud amounts based on observations and data from North Pole 25 in November 1982. 


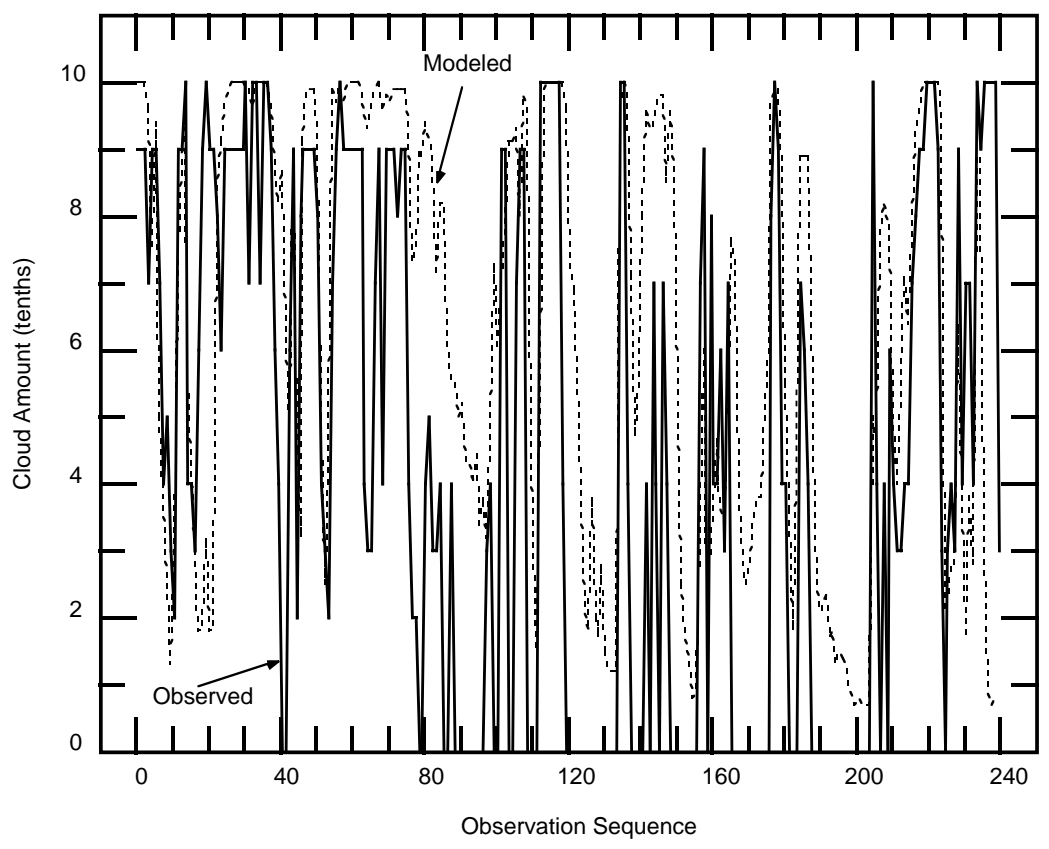

Figure 9. Temporal variability of 240 consecutive 3-hour observations of total cloud amount in November 1982 on North Pole 25 and our modeled total cloud amount based on eq 4 .

Naturally, using this algorithm to estimate total cloud amount has some limitations, since the observed cloud amount can result from any type of cloud from stratus to cirrus. Since each cloud type influences the radiation and temperature regime in the lower atmosphere differently, a prediction scheme based on only a single parameter, surface-layer temperature, must ultimately be an oversimplification. Nonstationarity in the physical processes in the lower atmosphere-caused, for example, by advecting and adjusting air masses or by the slow evolution of the atmospheric boundary layer during very stable stratification-can also distort the results. All of these problems (as well as some imperfect approximations in eq 4) should improve, however, with further work on this algorithm. In light of the results shown in Figures 8 and 9, we think eq 4 presents interesting prospects as an indirect method for estimating cloud amount in the polar regions, especially during the polar night. With the development of the International Arctic Buoy Program (IABP), in particular, and the consequent availability of simultaneously measured surface-layer temperatures from various parts of the Arctic Basin, our method could provide estimates of cloud amounts with coverage comparable to satellites.

\section{PARAMETERIZING THE LONGWAVE RADIATION BALANCE IN SEA ICE MODELS}

Longwave radiation is one of the key processes determining the rate at which sea ice forms in the polar regions in winter (Maykut 1986, Makshtas 1991a). This fact has led to numerous parameterizations for the longwave radiation balance of snow-covered sea ice. These have, in turn, been used to study the climatic significance of processes affecting ocean-atmosphere interaction in high latitudes, especially with coupled ocean-ice models in which the characteristics of the atmosphere are external parameters (e.g., Parkinson and Washington 1979, Hibler 1979). 
The longwave radiation emitted by a surface $\left(F_{\text {up }}\right)$ is described by the StefanBoltzmann law:

$$
F_{\text {up }}=\varepsilon \sigma T_{0}^{4},
$$

where $T_{0}$ is the surface temperature, $\varepsilon$ is the emittance of the surface, and $\sigma$ is the Stefan-Boltzmann constant.

The incoming longwave radiation from the atmosphere $\left(F_{\mathrm{dn}}\right)$ can be determined by an appropriate radiative transfer model (Kondratyev 1969, Curry and Ebert 1992). Using such models, however, requires data on the distribution of air temperature and humidity up to heights of at least $30 \mathrm{~km}$. Therefore, since the works of Brunt (1952) and Ångström (Geiger 1965, Matveev 1969), $F_{\mathrm{dn}}$ has been parameterized from standard meteorological observations using its empirical dependence on cloud amount and on the temperature and humidity of the atmospheric surface layer. In these parameterizations, the incoming longwave radiation is estimated from

$$
F_{\mathrm{dn}}=\varepsilon_{*}(n, T, e) \sigma T^{4},
$$

where $\varepsilon_{*}$ is the effective longwave emittance of the atmosphere, a function of cloud amount and air temperature $(T)$ and vapor pressure $(e)$ at a height of $2 \mathrm{~m}$.

Many functional expressions for the effective emittance of the atmosphere have been published. These are generally based on readily available observations and contain empirical coefficients obtained with a variety of temporal averaging methods. We consider here some frequently used functions.

\section{Brunt's method}

In Brunt's (1952) parameterization (e.g., Matveev 1969), $\varepsilon_{*}$ for a clear sky depends only on the water vapor content of the atmosphere and is described by

$$
\varepsilon_{*}=a_{\mathrm{B}}+b_{\mathrm{B}} e^{1 / 2},
$$

where $e$ is the vapor pressure in millibars, and $a_{\mathrm{B}}$ and $b_{\mathrm{B}}$ are empirical coefficients.

On the basis of observations in middle latitudes, Brunt found $a_{\mathrm{B}}=0.526$ and $b_{\mathrm{B}}=0.065$. These coefficients, however, are not universal; Kondratyev (1969) shows that their values change with the measurement site. Below we will show Marshunova's (1961) confirmation of this site dependence.

Brunt deduced the longwave radiation balance $\left(B=F_{\mathrm{up}}-F_{\mathrm{dn}}\right)$ by introducing a cloud multiplier. That is, the longwave radiation balance in the presence of clouds is

$$
B=B_{0}\left(1-c_{\mathrm{B}} n\right),
$$

where $n$ is fractional total cloud amount, $B_{0}$ is the longwave radiation balance for a clear sky, and $c_{\mathrm{B}}$ is the average weighting coefficient for all types of clouds. For latitudes above $60^{\circ} \mathrm{N}, c_{\mathrm{B}}=0.81$ (Berliand 1956).

\section{Marshunova's method}

Marshunova's (1961) parameterization is essentially an application of Brunt's methods to meteorological conditions in the Arc-
Table 6. The coefficients $a_{\mathrm{M}}$ and $b_{\mathrm{M}}$ for use in eq 9, derived by Marshunova (1961) from observations at various Arctic stations.

\begin{tabular}{lcc} 
& $\mathrm{a}_{M}$ & $\mathrm{~b}_{M}$ \\
\hline Tikhaya Bay & 0.61 & 0.073 \\
Cape Zhelaniya & 0.61 & 0.073 \\
Chetyrekhstolbovoy Island & 0.69 & 0.047 \\
Cape Schmidt & 0.69 & 0.047 \\
NP-3, NP-4, 1954-1957 & 0.67 & 0.050 \\
\hline
\end{tabular}


Table 7. Monthly averages of the coefficient $c_{M}$ for use in eq 9, derived by Marshunova (1961) from observations at various Arctic stations.

\begin{tabular}{lcccccccccccc} 
& $J$ & $F$ & $M$ & $A$ & $M$ & $J$ & $J$ & $A$ & $S$ & $O$ & $N$ & $D$ \\
\hline Tikhaya Bay & 0.27 & 0.29 & 0.29 & 0.24 & 0.24 & 0.22 & 0.19 & 0.19 & 0.21 & 0.25 & 0.26 & 0.28 \\
Cape Zhelaniya & 0.29 & 0.29 & 0.29 & 0.24 & 0.24 & 0.22 & 0.19 & 0.18 & 0.21 & 0.22 & 0.26 & 0.28 \\
Chetyrekhstolbovoy Island & 0.27 & 0.27 & 0.25 & 0.24 & 0.22 & 0.19 & 0.16 & 0.19 & 0.22 & 0.25 & 0.25 & 0.27 \\
Cape Schmidt & 0.25 & 0.25 & 0.20 & 0.25 & 0.24 & 0.18 & 0.16 & 0.19 & 0.22 & 0.25 & 0.27 & 0.26 \\
NP-3, NP-4, 1954-1957 & 0.30 & 0.30 & 0.30 & 0.28 & 0.27 & 0.24 & 0.22 & 0.23 & 0.27 & 0.29 & 0.30 & 0.30 \\
\hline
\end{tabular}

tic. The coefficients $a_{\mathrm{M}}$ and $b_{\mathrm{M}}$ are different, however, and accounting for the influence of clouds occurs directly in the formula for $F_{\mathrm{dn}}$ :

$$
\varepsilon_{*}=\left(a_{\mathrm{M}}+b_{\mathrm{M}} e^{1 / 2}\right)\left(1+c_{\mathrm{M}} n\right),
$$

where $n$ is again the fractional total cloud amount. Tables 6 and 7 list the $a_{\mathrm{M}}, b_{\mathrm{M}}$, and $c_{M}$ coefficients that Marshunova obtained from monthly averaged values of $B$ and $n$ observed at several polar stations and on drifting stations NP-3 and NP-4 in 1954-1957.

We see from Tables 6 and 7 that the empirical coefficients in eq 9 have clear spatial and temporal variability and are, thus, not universal. The variations in $c_{M}$ (Table 7) are especially pronounced. The variability in $a_{\mathrm{M}}, b_{\mathrm{M}}$, and $c_{\mathrm{M}}$ is likely connected with the types of air masses and clouds prevalent in a region, a variability we earlier documented in Table 1.

\section{Maykut and Church's method}

On analyzing 3000 hourly observations of air temperature, humidity, incoming longwave radiation, and cloud amount collected during a year at Barrow, Alaska, Maykut and Church (1973) developed the following expression for the effective emittance of the polar atmosphere:

$$
\varepsilon_{*}=0.7855\left(1+0.2232 n^{2.75}\right),
$$

where, as above, $n$ is the fractional total cloud amount. The difference between this and previous parameterizations is that here the influence of water vapor on incoming longwave radiation is taken into account indirectly in the empirical coefficients.

\section{Satterlund's method}

For parameterizing the effective emittance, Satterlund (1979) offers a function of air temperature and vapor pressure that Brutsaert (1982) claims describes longwave radiation well at low temperatures:

$$
\varepsilon_{*}=1.08\left[1-\exp \left(-e^{T / 2016}\right)\right],
$$

where $T$ is in kelvins and $e$ is in millibars. As with Brunt's method, Satterlund accounts for cloud effects by using a multiplier in the longwave radiation balance as in eq 8 .

\section{König-Langlo and Augstein's method}

For effective emittance, König-Langlo and Augstein (1994; henceforth, KL\&A) suggest

$$
\varepsilon_{*}=a_{K}+b_{\mathrm{K}} n^{3},
$$


Table 8. Observed and various modeled values of the longwave radiation balance ( $B$, top number) and incoming longwave radiation $\left(F_{\mathrm{dn}}\right.$, bottom number) in $\mathrm{W} / \mathrm{m}^{2}$.

\begin{tabular}{|c|c|c|c|c|c|c|}
\hline & \multicolumn{6}{|c|}{ Cloud amount } \\
\hline & \multicolumn{2}{|c|}{$0-10$} & \multirow{2}{*}{\multicolumn{2}{|c|}{$\frac{0-2}{110 \text { Observations }}$}} & \multicolumn{2}{|c|}{$8-10$} \\
\hline & \multicolumn{2}{|c|}{744 Observations } & & & \multicolumn{2}{|c|}{283 Observations } \\
\hline & Mean & Std & Mean & Std & Mean & Std \\
\hline \multirow[t]{2}{*}{ ISW Observations* } & 15.0 & 18.2 & 42.8 & 5.5 & -3.4 & 6.3 \\
\hline & 198.4 & 33.6 & 154.2 & 13.5 & 228.3 & 19.0 \\
\hline \multirow[t]{2}{*}{ Brunt, eq 7} & 41.1 & 19.4 & 72.2 & 5.8 & 21.5 & 3.8 \\
\hline & 171.7 & 34.6 & 123.9 & 12.0 & 203.1 & 17.6 \\
\hline \multirow[t]{2}{*}{ Marshunova, eq 9} & 44.7 & 9.4 & 59.2 & 3.8 & 35.5 & 3.3 \\
\hline & 171.6 & 27.7 & 139.7 & 14.1 & 193.0 & 20.6 \\
\hline \multirow[t]{2}{*}{ Maykut, eq 10} & 27.3 & 11.1 & 38.7 & 3.4 & 14.8 & 4.8 \\
\hline & 189.4 & 27.2 & 160.6 & 13.0 & 214.1 & 17.9 \\
\hline \multirow[t]{2}{*}{ Satterlund, eq 11} & 33.4 & 16.3 & 59.6 & 4.3 & 17.0 & 2.9 \\
\hline & 179.5 & 32.6 & 136.5 & 15.0 & 207.6 & 18.2 \\
\hline \multirow[t]{2}{*}{ KL\&A, eq 12} & 23.5 & 14.8 & 38.8 & 3.4 & 6.5 & 6.3 \\
\hline & 193.2 & 30.6 & 160.6 & 13.0 & 222.5 & 19.2 \\
\hline
\end{tabular}

* The observations are from Ice Station Weddell in May 1992. "Mean" is the average value for the indicated cloud amount; "Std" is the standard deviation of the values in that category.

where $n$ is again the fractional total cloud amount, and $a_{\mathrm{K}}$ and $b_{\mathrm{K}}$ are empirical coefficients. As in Maykut and Church's parameterization, these $a_{\mathrm{K}}$ and $b_{\mathrm{K}}$ coefficients implicitly include humidity effects.

König-Langlo and Augstein obtained $a_{\mathrm{K}}=0.765$ and $b_{\mathrm{K}}=0.22$ on the basis of visual observations of cloud amount and measurements of incoming longwave radiation with an Eppley PIR pyrgeometer at two polar stations (Ny-Ålesund, $70^{\circ} 56^{\prime} \mathrm{N}, 11^{\circ} 56 \mathrm{E}$; and Georg von Neumayer, $\left.70^{\circ} 39^{\prime} \mathrm{S}, 8^{\circ} 15^{\prime} \mathrm{W}\right)$. KL\&A's $\varepsilon_{*}$ differs from Maykut and Church's by its stronger dependence on cloud amount.

\section{New test of the longwave parameterizations}

We obtained new data for evaluating the five parameterizations described above during the drift of the Russian-American Ice Station Weddell (ISW) in the western Weddell Sea from February to June 1992 (Andreas et al. 1992, Claffey et al. 1995). During this period, in the center of a drifting 1-km-wide ice floe, we made continuous, hourly averaged measurements of the components of the longwave radiation budget and the usual meteorological variables with both Russian and American sensors. The radiation measurements, in particular, showed good agreement among the various instruments (Claffey et al. 1995).

Table 8 lists some of the statistical results of measurements and calculations for all of the observations made in May 1992 on ISW. We focus on May because we have data for the entire month and because the shortwave components-which might complicate our measuring and interpreting the longwave radiation-were small. Because cloud amount at ISW had a U-shaped distribution (Fig. 4), Table 8 treats the radiation values for clear (0-2) and overcast (8-10) skies separately, regardless of other weather conditions. 
On studying Table 8, we see that the best agreement between the observations and the various incoming longwave parameterizations that we are considering is for König-Langlo and Augstein's (1994) method. With this parameterization, the difference between the measured values and those calculated with eq 12 (i.e., the $F_{\text {dn }}$ rows in Table 8 ) does not exceed $4 \%$. This is approximately the experimental error in $F_{\mathrm{dn}}$. Maykut and Church's (1973) parameterization is also good, but not quite as good as KL\&A's. The other three parameterizations for $F_{\mathrm{dn}}$ in Table 8 are significantly worse.

Although in Table 8 the error in evaluating $B$ for clear skies ( $0-2$ column) is of the order of $10 \%$, the error increases to $100 \%$, if we consider all the observations (0-10 column) during the month. Notice, too, for overcast skies (8-10 column), when the absolute values of $B$ are small, even the sign of $B$ changes. Remember, the value of the longwave radiation balance, calculated from experimental data, represents a small difference between large values of $F_{\mathrm{dn}}$ and $F_{\mathrm{up}}$ and, accordingly, has a large relative error. Consequently, parameterizing it is difficult. Nevertheless, the data from ISW confirm that the recent parameterization for incoming longwave radiation by KL\&A is good for polar seas covered by ice during the polar night.

Figure 10 shows the temporal variability of the incoming longwave radiation for May observed on ISW and estimated with the five parameterizations under
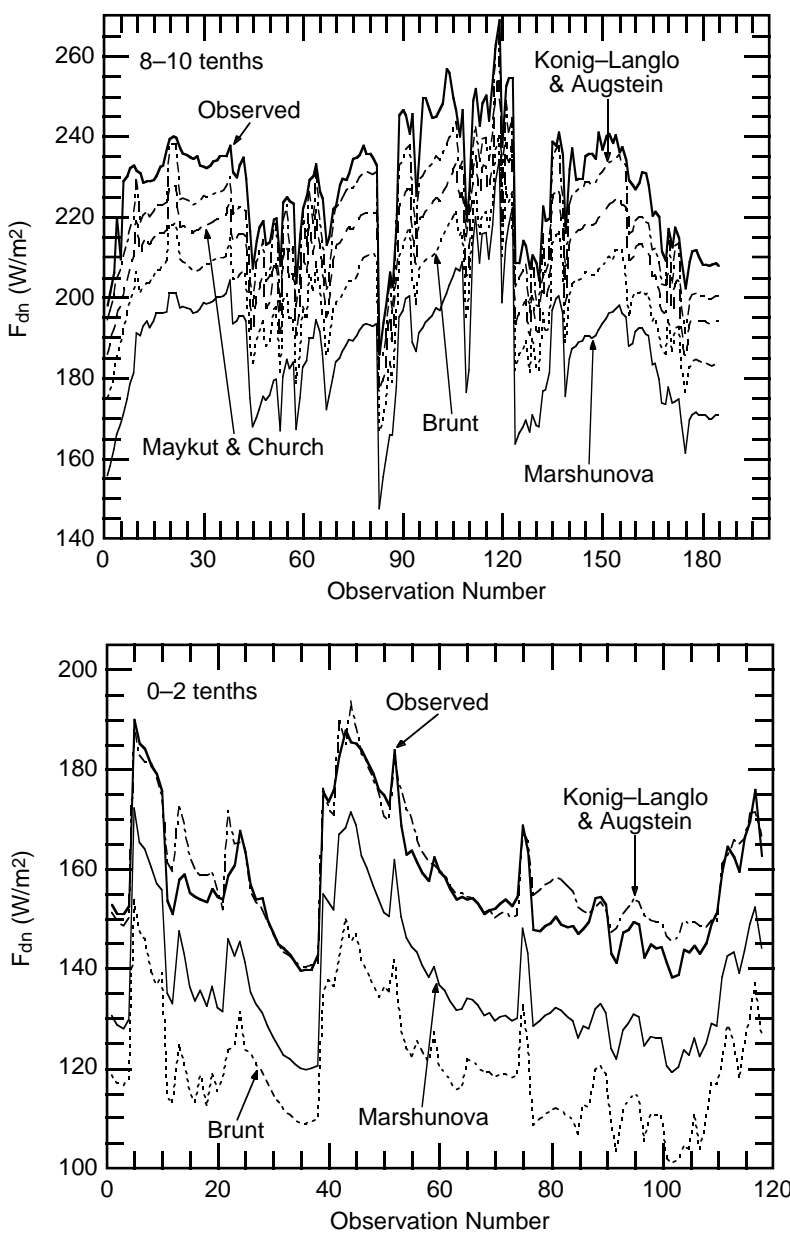

Figure 10. Measured incoming longwave radiation during May 1992 on Ice Station Weddell and predictions of it using the equations of Brunt, Marshunova, Maykut and Church, Satterlund, and König-Langlo and Augstein. The upper panel is a temporal sequence when the total cloud amount was 8 to 10 tenths. Satterlund's scheme produces estimates between the Brunt and Maykut and Church estimates and is, thus, left out of this panel for clarity. The lower panel is for observations when the total cloud amount was 0 to 2 tenths. Because Maykut and Church's scheme produces estimates similar to KLEA's and because Satterlund's scheme yields results similar to Marshunova's, we leave these two traces out of this panel for clarity. 
consideration. Although the estimates may differ from the observed radiation for both the clear-sky and overcast-sky cases, each of the five parameterization schemes does predict temporal behavior that coincides with that in the experimental data.

Though we here confirm KL\&A's longwave parameterization, eq 12, with only Antarctic data, remember that KL\&A formulated that relation on the basis of both Arctic and Antarctic data. Consequently, we have no reason to suspect that it is inappropriate to use it in our Arctic sensitivity studies in the next section.

\section{MODEL SENSITIVITY TO THE DESCRIPTION OF LONGWAVE RADIATION}

An equation for the heat budget of the upper surface is a necessary component of prognostic and climatic sea ice models regardless of their complexity (Maykut and Untersteiner 1971, Parkinson and Washington 1979, Makshtas et al. 1988, Ebert and Curry 1993). In contrast with Maykut and Untersteiner's (1971) nonstationary, one-dimensional sea ice model, in which the characteristics of the energy exchange between the atmosphere and the ocean were prescribed, in subsequent models the turbulent surface fluxes of sensible $\left(H_{\mathrm{s}}\right)$ and latent heat $\left(H_{\mathrm{L}}\right)$, the longwave radiation balance $(B)$, and the shortwave radiation balance are internal parameters of the model. That is, these are simulated conditions of the sea ice cover and, as such, are prescribed by the parameters of the atmospheric surface layer.

Above we showed that, using the same input data, calculations of the longwave radiation at a sea ice surface differ depending on which of several popular parameterizations we use. It is, thus, interesting to consider how applying these parameterizations in a sea ice model might affect the computed equilibrium thickness of the sea ice. For this purpose, we perform several numerical experiments using the one-dimensional sea ice model described by Makshtas (1991b).

As the external parameters in the model, we used the 3-hour standard meteorological observations from October 1982 to October 1983 on drifting station North Pole 25 , which was above $85^{\circ} \mathrm{N}$ during that period. For the daily averaged value of incoming shortwave radiation, we averaged continuous measurements of the

global solar radiation. The heat flux from the ocean to the bottom of the sea ice was assigned the usual value, $2 \mathrm{~W} / \mathrm{m}^{2}$ (e.g., Parkinson and Washington 1979).

For calculating the turbulent surface heat fluxes, we use the bulk-aerodynamic method (e.g., Andreas 1996):

$$
\begin{aligned}
& H_{\mathrm{s}}=\rho c_{\mathrm{p}} C_{\mathrm{Hr}} U_{\mathrm{r}}\left(T_{\mathrm{s}}-T_{\mathrm{r}}\right), \\
& H_{\mathrm{L}}=\rho L_{\mathrm{v}} C_{\mathrm{Er}} U_{\mathrm{r}}\left(Q_{\mathrm{s}}-Q_{\mathrm{r}}\right),
\end{aligned}
$$

where $\rho=$ the air density

$c_{\mathrm{p}}=$ the specific heat of air at constant pressure

$L_{\mathrm{v}}=$ the latent heat of vaporization or sublimation

$U_{\mathrm{r}}=$ the wind speed at reference height $r$

$T_{\mathrm{S}}$ and $Q_{\mathrm{S}}=$ the temperature and specific humidity of the air at the surface

$T_{\mathrm{r}}$ and $Q_{\mathrm{r}}=$ the temperature and humidity at height $r$.

The crux of the bulk-aerodynamic method is defining the bulk transfer coefficients appropriate at height $r, C_{\mathrm{Hr}}$ and $C_{\mathrm{Er}}$. These are (e.g., Andreas and Murphy 1986) 


$$
\begin{aligned}
& C_{\mathrm{Hr}}=\frac{k^{2}}{\left[\ln \left(r / z_{0}\right)-\psi_{\mathrm{m}}(r / L)\right]\left[\ln \left(r / z_{\mathrm{T}}\right)-\psi_{\mathrm{h}}(r / L)\right]}, \\
& C_{\mathrm{Er}}=\frac{k^{2}}{\left[\ln \left(r / z_{0}\right)-\psi_{\mathrm{m}}(r / L)\right]\left[\ln \left(r / z_{\mathrm{Q}}\right)-\psi_{\mathrm{h}}(r / L)\right]} .
\end{aligned}
$$

Here $z_{0}, z_{\mathrm{T}}$, and $z_{\mathrm{Q}}$ are the roughness lengths for wind speed, temperature, and humidity, respectively, and $L$ is the Obukhov length, a stability parameter.

For the semiempirical stability functions for momentum $\left(\psi_{\mathrm{m}}\right)$ and heat $\left(\psi_{\mathrm{h}}\right)$ in eq 14, we use the following:

For stable stratification, $r / L \equiv \varsigma \geq 0$ (Launiainen and Vihma 1990),

$$
\psi_{\mathrm{m}}(\varsigma)=\psi_{\mathrm{h}}(\varsigma)=-[0.7 \varsigma+0.75(\varsigma-14.3) \exp (-0.35 \varsigma)+10.7]
$$

For unstable stratification, $\varsigma \geq 0$ (Paulson 1970),

$$
\begin{aligned}
& \psi_{\mathrm{m}}(\varsigma)=2 \ln [(1+y) / 2]+\ln \left[\left(1+y^{2}\right) / 2\right]-2 \arctan (y)+\pi / 2 \\
& \psi_{\mathrm{h}}(\varsigma)=2 \ln \left[\left(1+y^{2}\right) / 2\right]
\end{aligned}
$$

where

$$
y=(1-16 \varsigma)^{1 / 4}
$$

We ran the model with cyclic boundary conditions such that the thicknesses of the ice and snow at the end of a year were used as inputs to the new year with the same one-year (i.e., October 1982 to October 1983) NP-25 meteorological data repeating. Computations ended when the ice thickness reached equilibrium.

In modeling sea ice there are usually two main problems. First, as mentioned above, is choosing parameterizations for the main components of the surface heat budget. Second is the external meteorological information. Because the iterative procedure in models typically uses a one-day time step, daily averaged values of the external parameters are necessary. Such information can be obtained in two ways. One way is to average the 3-hour meteorological observations for each day. Another is to interpolate the monthly averaged fields computed from many years of data and tabulated in an atlas, Gorshkov (1983) for example, to obtain daily values. The input data that this second method yields are more smooth than data from the first method but less accurate.

For example, interpolating monthly data to daily values must produce a time series of cloud amount that varies monotonically through the month in the same manner year after year. Such a series is of little use for investigating interannual variability.

On the other hand, producing 3-hour observations for the entire Arctic Basin requires accurately interpolating daily averaged data measured at nonuniformly distributed drifting buoys and polar stations. We mentioned above that, in principle, daily averaged surface temperature, at least, should be available for the entire basin from these sources. Then, using the method described above, it should 
Table 9. Modeled characteristics of a sea ice cover based on various longwave parameterizations and the data from North Pole 25 from October 1982 to October 1983. Computed sea ice variables are the maximum and minimum thickness, the amplitude $(\Delta h)$ of the annual variation in thickness, and the dates on which melting first begins in the snowpack and cooling in the sea ice begins.

\begin{tabular}{|c|c|c|c|c|c|c|}
\hline & Experiment & $\begin{array}{c}\text { Maximum } \\
(m)\end{array}$ & $\begin{array}{c}\text { Minimum } \\
(m)\end{array}$ & $\begin{array}{l}\Delta h \\
(m)\end{array}$ & Melting & Cooling \\
\hline 1. & Brunt, eq 7 , day* & 6.50 & 5.78 & 0.72 & May 20 & Sept 10 \\
\hline 2. & Marshunova, eq 9, day & 4.40 & 3.45 & 0.95 & May 25 & Sept 11 \\
\hline 3. & Maykut, eq 10, day & 4.96 & 4.19 & 0.77 & May 24 & Sept 10 \\
\hline 4. & Satterlund, eq 11, day & 5.09 & 4.17 & 0.92 & May 24 & Sept 12 \\
\hline 5. & KL\&A, eq 12, day & 3.94 & 2.93 & 1.01 & May 26 & Sept 12 \\
\hline 6. & KL\&A, eq 12, day, rec & 3.87 & 2.85 & 1.02 & May 25 & Sept 12 \\
\hline 7. & KL\&A, eq 12, month & 4.67 & 3.83 & 0.84 & May 24 & Sept 11 \\
\hline 8. & KL\&A, eq 12, month, sum & 4.61 & 3.77 & 0.84 & May 25 & Sept 11 \\
\hline 9. & KL\&A, eq 12, month, win & 3.99 & 2.97 & 1.02 & May 25 & Sept 12 \\
\hline 10. & Marshunova, eq 9, month & 4.36 & 3.39 & 0.97 & May 29 & Sept 11 \\
\hline 11. & Marshunova, eq 9, month, sum & 4.37 & 3.41 & 0.96 & May 27 & Sept 11 \\
\hline 12. & Marshunova, eq 9 , month, win & 4.38 & 3.42 & 0.96 & May 27 & Sept 11 \\
\hline
\end{tabular}

* To identify the different numerical experiments, we use the following shorthand: "day" used daily averaged observations of total cloud amounts; "day, rec" used daily averaged total cloud amounts for winter reconstructed from air temperature using eq 4; "month" used monthly cloud data interpolated to daily values; "month, sum" used daily averaged data for the winter but monthly averaged cloud data interpolated to daily values for the summer; "month, win" used daily averaged data for the summer but monthly averaged data interpolated to daily values for the winter.

also be possible to estimate daily averaged total cloud amount on an arbitrary grid throughout the basin.

The method for describing cloud amount can, of course, have a significant influence on the computed longwave radiation balance in particular. The parameterizations for $F_{\mathrm{dn}}$ and $B$ by Brunt, Marshunova, and Satterlund account for clouds with linear functions. Therefore, monthly averaged values of $F_{\mathrm{dn}}$ and $B$ should not differ regardless of whether they were obtained from 3-hour cloud observations averaged to daily values or from monthly cloud amounts interpolated to daily values - provided, of course, that the monthly cloud values are based on the same 3-hour observations. In contrast, Maykut and Church's and KL\&A's parameterizations for $F_{\mathrm{dn}}$ and $B$ depend nonlinearly on cloud amount. For these, the type of averaging is crucial.

Table 9 lists numerical model calculations of the equilibrium sea ice thickness and related variables computed using the various parameterizations for longwave radiation that we have been discussing and the various ways of representing cloud data. All the other meteorological information used in these numerical experiments, including the incoming shortwave radiation, are daily averages computed from 3-hour observations.

We see in Table 9 that the spread in the computed maximum and minimum ice thicknesses based on the various parameterizations for $F_{\mathrm{dn}}$ (i.e., experiments 1-5) is rather large. The seasonal amplitude in ice thickness also varies widely-from $0.72 \mathrm{~m}$ with the Brunt parameterization to $1.01 \mathrm{~m}$ with the KL\&A parameterization. The KL\&A parameterization (i.e., experiment 5) yields an equilibrium thickness closest to the usually accepted value (e.g., Semtner 1976, Hibler 1979). The results of experiment 6 in the table are also very interesting. Here the cloud amounts 
reconstructed from temperature using eq 4 lead to predictions that are virtually identical with experiment 5 , which we judge as the experiment closest to reality.

The calculated first day of melting in Table 9, nominally 24-26 May, is somewhat earlier than Yanes (1962, Fig. 1) would predict for $85^{\circ} \mathrm{N}$, about June 20. But his relation tracks the onset of "intense snow melting," while we record the first appearance of liquid water in the snowpack. A simulation by Jordan et al. (1998) of the seasonal cycle on NP-4, which was within $5^{\circ}$ latitude of the North Pole in 1956-57, also predicts a later date, June 18, for the onset of diurnal melting than we list in Table 9. But Yanes's results suggest melting is delayed by about 8 day for every $5^{\circ}$ increase in latitude. Hence, the NP-25 and NP-4 results are fairly compatible.

The "Cooling" column in Table 9 lists the date when the sea ice begins cooling again after the summer ablation season. The nominal date that we calculate as the beginning of cooling is 11-12 September. From thermocouples embedded in the sea ice at NP-4, Jordan et al. (1998) show that in 1956 cooling began at this station on about 28 August. Again, since NP-4 was $5^{\circ}$ farther north than NP-25, our modeled date for the onset of cooling is reasonable.

In experiments $7-12$, to evaluate model sensitivity to the method for describing the temporal variability in cloud amount, we used just the longwave parameterizations of KL\&A and Marshunova. In the Marshunova (1961) parameterization, we used the empirical coefficients listed in Tables 6 and 7 that derived from observations on the drifting stations. As we hinted above, it is clear in Table 9 that the Marshunova parameterization (i.e., experiments 2,10-12) is less sensitive to the method of obtaining cloud amounts than the KL\&A parameterization (experiments 5-9). Because KL\&A's parameterization has a cubic dependence on cloud amount, the three sensitivity experiments predict maximum ice thicknesses that range over $0.7 \mathrm{~m}$, depending on the method for determining cloud amount. We thus reiterate that, because the best model for $F_{\mathrm{dn}}$ was derived from nonaveraged data and depends nonlinearly on cloud amount, sea ice models employing it will be quite sensitive to the method of handling the cloud data.

In Table 9, experiments 5, 6, and 9 yield practically the same results. Likewise, experiments 7 and 8 produce almost identical ice thicknesses, but these differ essentially from the results in experiments 5,6 , and 9 . Table 10, which shows cal-

Table 10. Incoming longwave radiation (in $\mathrm{W} / \mathrm{m}^{2}$ ) during the winter of 1982-1983 on North Pole 25.

\begin{tabular}{llllll} 
& November & December & January & February & March \\
\hline Daily avg* & 163 & 160 & 137 & 149 & 168 \\
Reconstructed & $171(0.84)$ & $163(0.86)$ & $149(0.97)$ & $158(0.94)$ & $184(0.89)$ \\
Monthly avg, int & $160(0.93)$ & $152(0.88)$ & $135(0.97)$ & $145(0.96)$ & $162(0.88)$ \\
\hline
\end{tabular}

* "Daily avg" values are the observations averaged each day and then averaged for the month; "Reconstructed" values are the individual estimates computed using eq 4, averaged daily, and then averaged for the month; "Monthly avg, int" values are based on monthly data interpolated to daily values using a parabolic interpolation over three months. Figure 11 shows daily values of these various cloud amounts for November 1982. For the computed longwave radiation values, we used König-Langlo and Augstein's (1994) formula, (eq 12). Numbers in parentheses are the correlation coefficients between the daily averaged observed values of longwave radiation and the respective reconstructed and interpolated values. It is important to point out here that we calculated the monthly averaged values from daily averages observed on North Pole 25; these averages thus differ from those shown in Gorshkov (1983). 


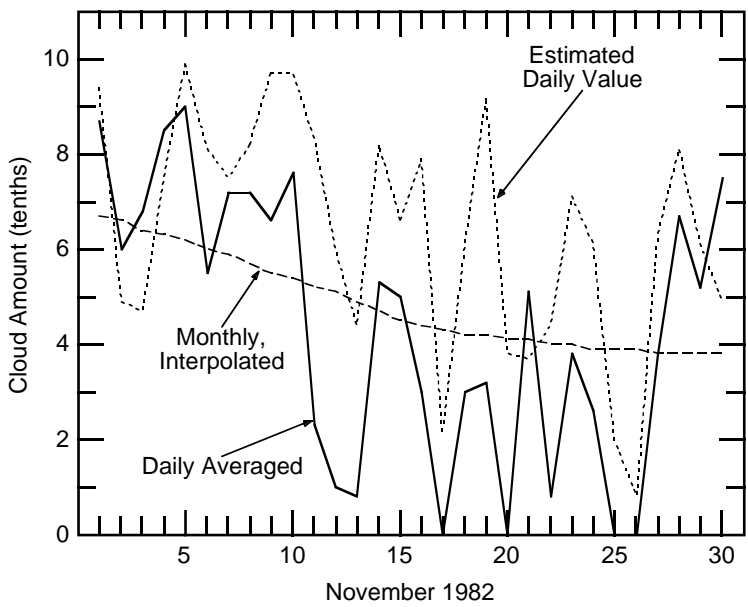

Figure 11. Temporal variability of total cloud amount for November 1982 on North Pole 25. The traces show 1) the 3-hour cloud observations averaged to daily values, 2) cloud amount estimates based on eq 4 using daily averaged temperature, and 3) cloud amounts estimated using monthly cloud data interpolated to daily values using a parabolic interpolation over three months.

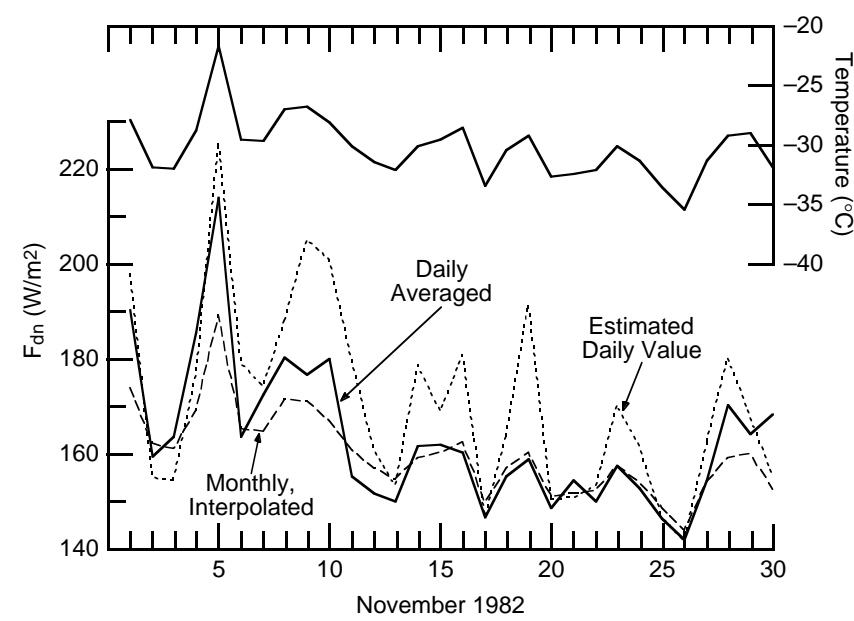

Figure 12. Temporal variability of the daily averaged surfacelayer air temperature and the incoming longwave radiation for November 1982 on North Pole 25. The computed values of $F_{d n}$ are based on eq 12 using 1) 3-hour cloud observations averaged to daily values, 2) monthly cloud data interpolated to daily values with a parabolic interpolation over three months, and 3) daily averaged cloud data estimated using eq 4 .

culations of longwave radiation for each winter month on North Pole 25 based on the KL\&A parameterization, explains the good agreement among these three cases.

We see in Table 10 and in Figure 12 that, despite the essential differences in the time series of cloud amounts used in the calculations (Fig. 11), the time series of calculated $F_{\mathrm{dn}}$ values correspond well with each other, both on average and in terms of the linear correlation coefficient. Although this good agreement may, at first, seem paradoxical, the formula used to estimate $F_{\mathrm{dn}}$ explains it. To obtain the longwave fluxes in Table 10 and in Figures 12, we used-from eq 6 and 12-

$$
F_{\mathrm{dn}}=\sigma T^{4}\left(a_{\mathrm{K}}+b_{\mathrm{K}} n^{3}\right) .
$$

Thus, the air temperature $T$ dominates the calculation. But remember, the correlation between $T$ and $n$ is also high. Consequently, because the surface-layer air tem- 

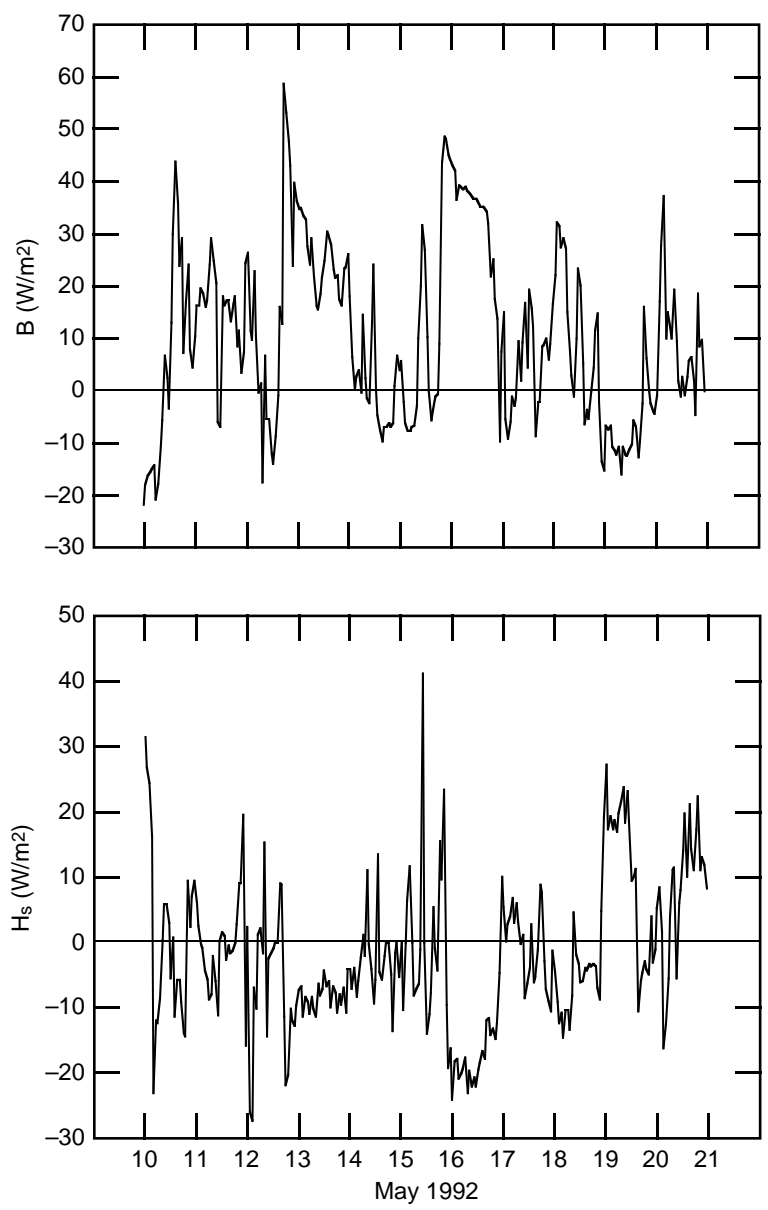

Figure 13. Temporal variability of the longwave radiation balance and the sensible heat flux for the middle 10 days in May 1992 on Ice Station Weddell. The radiation data are hourly averages; the sensible heat flux values derive from profile measurements of wind speed and air and surface temperature (Andreas et al. 1992).

perature in winter over Arctic sea ice depends largely on longwave radiation processes, that temperature, in effect, contains information on cloud amount.

Another process that dictates the close agreement among the equilibrium ice thicknesses in experiments 5, 6, and 9 is the feedback between the longwave radiation balance and the vertical turbulent surface flux of sensible heat, the main components of the surface heat budget in winter. That feedback is clear in the data from Ice Station Weddell: Figure 13 shows that an increase in the radiative cooling of the snow surface causes an increase in the temperature gradient in the atmospheric surface layer (and a corresponding increase in the downward sensible heat flux). Consequently, the traces of longwave radiation balance and sensible heat flux are almost mirror images. The one-dimensional sea ice model of Makshtas and Timachev (1992) also reproduces this feedback between sensible heat flux and net longwave radiation.

The large differences between the computed ice thicknesses in experiments 5 , 6 , and 9 and the thickness in experiments 7 and 8 result because of the absence of feedback between the sensible heat flux and the net longwave radiation in summer. During the summer, the snow and ice surface is near the melting point for long periods and, thus, accommodates changes in the net longwave radiation by changing phase rather than by exchanging sensible heat. Also, the strong dependence of $F_{\mathrm{dn}}$ on cloud amount (see eq 12 or 16), which in summer is usually 8-10 tenths (Table 2), sharpens the difference between the results for the two groups of 
experiments. For a prescribed shortwave radiation flux (i.e., one that does not depend on cloud conditions), the reduced variability in total cloud amount in summer caused by interpolating monthly averages to daily values results in greater equilibrium ice thicknesses in experiments 7 and 8 than those reported for Makshtas and Timachev's (1992) numerical experiments.

We thus believe that, for sea ice models driven by atmospheric data, reconstructing total cloud amount from air temperature provides sufficient accuracy for calculating the surface heat budget in the winter and, especially, for studying its monthly variability (Table 10). On the other hand, in summer, when the surface temperature is nearly constant at the melting point and the feedback between the main components of the surface heat budget is consequently weaker, models will require better cloud data and a more accurate description of cloud effects on shortwave and longwave radiation.

\section{CONCLUSIONS}

We summarize our results in the following conclusions:

- Our analysis of observations made on the North Pole drifting stations shows that the frequency distribution of total cloud amount in the Arctic Basin, especially in winter, is U-shaped. We fitted these histograms with beta distributions; Table 4 lists the fitting parameters. Since the mean of a quantity with a U-shaped distribution actually corresponds to the least likely value of the quantity, representing Arctic cloud amounts with monthly averaged values is a flawed approach.

- The series of meteorological observations on drifting stations that worked above $77^{\circ} \mathrm{N}$ from 1955 through 1991 suggests reduced frequency of clear skies in winter and of overcast skies in summer (see Fig. 6 and 7). The former may be associated with increasing atmospheric pollution in the Arctic; and the latter, with a shift in the general atmospheric circulation.

- We developed a reliable method for estimating total cloud amount in winter from atmospheric surface-layer temperature. This method yields a frequency distribution for total cloud amount that has a U-shaped distribution-as it should —although the input air temperature values are normally distributed. Because modeling results based on this method compare reasonably well with observations, the method is an algorithm that could improve the remote sensing of total cloud amount.

- Meteorological data collected on Ice Station Weddell suggest that KönigLanglo and Augstein's (1994) method for handling total cloud amount in parameterizations of incoming longwave radiation in polar regions is the best among five popular candidates.

- We have confirmed the value of the KL\&A parameterization through numerical experiments using a one-dimensional thermodynamic sea ice model and an annual cycle (October 1982 to October 1983) of meteorological observations from North Pole 25. This modeling shows that, of the five parameterizations considered, the one from KL\&A produces estimates of equilibrium sea ice thickness and its seasonal variability closest to existing notions about those quantities (Table 9). Associated calculations suggest that in winter the atmospheric surface-layer temperature is largely an integrated parameter because of the essential three-way feedback among air tempera- 
ture, clouds, and longwave radiation. As such, temperature data alone are sufficient for estimating total cloud amounts with our statistical model. These cloud amounts, in turn, facilitate estimating longwave fluxes with sufficient accuracy for sea ice modeling.

\section{LITERATURE CITED}

Aivazyan, S.A., I.S. Enyukov, and L.D. Meshalkin (1983) Applied Statistics: Basis for Modeling and Preliminary Data Processing (in Russian). Moscow: Finances and Statistics.

Andreas, E.L (1996) The atmospheric boundary layer over polar marine surfaces. U.S. Army Cold Regions Research and Engineering Laboratory, Hanover, New Hampshire, Monograph 96-2.

Andreas, E.L, and B. Murphy (1986) Bulk transfer coefficients for heat and momentum over leads and polynyas. Journal of Physical Oceanography, 16: 1875-1883.

Andreas, E.L, K.J. Claffey, A.P. Makshtas, and B.V. Ivanov (1992) Atmospheric sciences on Ice Station Weddell. Antarctic Journal of the U.S., 27(5): 115-117.

Barry, R.G. (1984) The nature and significance of cloud-cryosphere interactions in the marginal snow and ice zones. In Climatic Changes on a Yearly to Millennial Basis, (N.-A. Mörner and W. Karlén, Ed.), p. 605-607. Dordrecht: D. Reidel.

Berliand, M.E. (1956) The Prediction and Regulation of the Heat Condition of the Atmospheric Surface Layer (in Russian). Leningrad: Gidrometeoizdat.

Blanchet, J.-P. (1989) Toward estimation of climatic effects due to Arctic aerosols. Atmospheric Environment, 23: 2609-2625.

Brunt, D. (1952) Physical and Dynamical Meteorology, 2nd Edition. London: Cambridge University Press.

Brutsaert, W.H. (1982) Evaporation into the Atmosphere. Dordrecht: D. Reidel.

Cess, R.D., G.L. Potter, J.P. Blanchet, G.J. Boer, S.J. Ghan, J.T. Kiehl, H. Le Treut, Z.-X. Li, X.-Z. Liang, J.F.B. Mitchell, J.-J. Morcrette, D.A. Randall, M.R. Riches, E. Roeckner, U. Schlese, A. Slingo, K.E. Taylor, W.M. Washington, R.T. Wetherald, and I. Yagai (1989) Interpretation of cloud-climate feedback as produced by 14 atmospheric general circulation models. Science, 245: 513-516.

Claffey, K.J., E.L Andreas, A.P. Makshtas, and B.V. Ivanov (1995) In situ measurements of the surface temperature in the western Weddell Sea. Preprints, 4 th Conference on Polar Meteorology and Oceanography, American Meteorological Society, Boston, p. 86-90.

Curry, J.A., and E.E. Ebert (1990) Sensitivity of the thickness of Arctic sea ice to the optical properties of clouds. Annals of Glaciology, 14: 43-46.

Curry, J.A., and E.E. Ebert (1992) Annual cycle of radiation fluxes over the Arctic Ocean: Sensitivity to cloud optical properties. Journal of Climate, 5: 1267-1280.

Dmitriev, A.A. (1994) The Variability of the Atmospheric Processes in the Arctic and Its Application in Long-Time Forecasts (in Russian). St. Petersburg: Gidrometeoizdat.

Doronin, Yu.P., and D.E. Kheisin (1975) Sea Ice (in Russian). Leningrad: Gidrometeoizdat. English translation available as Doronin, Yu.P. and D.E. Kheisin (1977) Sea Ice. New Delhi: Amerind Publishing Co.

Ebert, E.E., and J.A. Curry, (1993) An intermediate one-dimensional thermodynamic sea ice model for investigating ice-atmosphere interactions. Journal of Geophysical Research, 98: 10,085-10,109.

Geiger, R. (1965) The Climate Near the Ground. Cambridge, Mass.: Harvard University Press. 
Gorshkov, S.G. (Ed.) (1983) World Ocean Atlas, Volume 3: Arctic Ocean (in Russian). New York: Pergamon Press.

Harr, M.E. (1977) Mechanics of Particulate Media: A Probabilistic Approach. New York: McGraw-Hill.

Hibler, W.D., III (1979) A dynamic thermodynamic sea ice model. Journal of Physical Oceanography, 9: 815-846.

Huschke, R.E. (1969) Arctic cloud statistics from "air-calibrated" surface weather observations. Memorandum RM-6173-PR, Rand Corporation, Santa Monica, California.

Jordan, R.E., E.L Andreas, and A.P. Makshtas (1998) A study of the surface heat budget of the Arctic Ocean based on data from North Pole 4. Journal of Geophysical Research, submitted.

Key, J.R., R.A. Silcox, and R.S. Stone (1996) Evaluation of surface radiative flux parameterizations for use in sea ice models. Journal of Geophysical Research, 101: 3839-3849.

Kondratyev, K.Ya. (1969) Radiation in the Atmosphere. New York: Academic Press. König-Langlo, G., and E. Augstein (1995) Parameterization of the downward longwave radiation at the Earth's surface in polar regions. Meteorologische Zeitschrift, 3: 343-347.

Launiainen, J., and T. Vihma (1990) Derivation of turbulent surface fluxes-An iterative flux-profile method allowing arbitrary observing heights. Environmental Software, 5: 113-124.

Makshtas, A.P. (1991a) The Heat Budget of Arctic Ice in the Winter. Cambridge, England: International Glaciological Society.

Makshtas, A.P. (1991b) The processes of air-sea interaction in the North Polar region (in Russian). In Atmosphere-Ocean Interaction in the North Polar Region (A.F. Treshnikov and G.V. Alekseev, Eds.), p. 47-91. Leningrad: Gidrometeoizdat.

Makshtas, A.P., and V.F. Timachev (1992) The sensitivity of a thermodynamic model of sea ice to the parameterization of short and long-wave radiation (in Russian). Trudy, Arkticheskogo i Antarkticheskogo Naucho-Issledovatelskogo Instituta, 430: 116-137.

Makshtas, A.P., L.S. Nazarenko, and S.V. Shutilin (1988) A model of the sea ice cover of the Arctic Basin (in Russian). Akademii Nauk SSSR, Novosibirsk Vychislitelnyi Tsentr, 96-116.

Marshunova, M.S. (1961) Principal characteristics of the radiation balance of the underlying surface and of the atmosphere in the Arctic (in Russian). Trudy, Arkt. Antarkt. Naucho-Issl. Inst., 229: 5-53. Translated in Soviet Data on the Arctic Heat Budget and Its Climatic Influence. Memorandum RM-5003-PR (J.O. Fletcher, B. Keller, and S.M. Olenicoff, Eds.), p. 51-131. Santa Monica, California: Rand Corporation. [NTIS: AD-632995.]

Marshunova, M.S., and A.A. Mishin (1994) Handbook of the radiation regime of the Arctic Basin (results from the drift stations). Technical Report APL-UW TR 9413 (V.F. Radionov and R. Colony, Eds.), Applied Physics Laboratory, University of Washington, Seattle.

Matveev, L.T. (1969) The Fundamentals of Meteorology: Physics of the Atmosphere (in Russian). Leningrad: Gidrometeoizdat.

Maykut, G.A. (1986) The surface heat and mass balance. In The Geophysics of Sea Ice (N. Untersteiner, Ed.), p. 395-463, New York: Plenum. 
Maykut, G.A., and P.E. Church (1973) Radiation climate of Barrow, Alaska. Journal of Applied Meteorology, 12: 620-628.

Maykut, G.A., and N. Untersteiner (1971) Some results from a time-dependent thermodynamic model of sea ice. Journal of Geophysical Research, 76: 1550-1575.

Moritz, R.E., J.A. Curry, A.S. Thorndike, and N. Untersteiner (Ed.) (1993) SHEBA, a research program on the Surface Heat Budget of the Arctic Ocean: Prospectus. ARCSS/OAII Rep. No. 3, Polar Science Center, University of Washington, Seattle.

National Snow and Ice Data Center (NSIDC) (1996) Arctic Ocean Snow and Meteorological Observations from Drifting Stations: 1937, 1950-1991, Version 1.0. CD-ROM, University of Colorado, Boulder. [Available from nsidc@kryos.colorado.edu.]

Overland, J.E., and P.S. Guest (1991) The Arctic snow and air temperature budget over sea ice during winter. Journal of Geophysical Research, 96: 4651-4662.

Parkinson, C.L., and W.M. Washington (1979) A large-scale numerical model of sea ice. Journal of Geophysical Research, 84: 311-337.

Paulson, C.A. (1970) The mathematical representation of wind speed and temperature profiles in the unstable atmospheric surface layer. Journal of Applied Meteorology, 9: 857-861.

Prik, Z.M. (1965) Climate of the Soviet Arctic (Meteorological Regime) (in Russian). Leningrad: Gidrometeoizdat.

Raschke, E. (1987) Report of the International Satellite Cloud Climatology Project (ISCCP) workshop on cloud algorithms in the polar regions. WMO/TD-No. 170, World Meteorological Organization, Geneva.

Satterlund, D.R. (1979) An improved equation for estimating long-wave radiation from the atmosphere. Water Resources Research, 15: 1649-1650.

Semtner, A.J., Jr. (1976) A model for the thermodynamic growth of sea ice in numerical investigations of climate. Journal of Physical Oceanography, 6: 379-389.

Shaw, G.E. (1995) The Arctic haze phenomenon. Bulletin of the American Meteorological Society, 76: 2403-2413.

Ventcel, E.C. (1964) Probability Theory (in Russian). Moscow: Nauka.

Voskresenskii, A.I., and N.N. Bryazgin (1988) On monitoring clouds in the Arctic (in Russian). In Monitoring of the Arctic Climate, (A.I. Voskresenskii, Ed.), p. 8795. Leningrad: Gidrometeoizdat.

Warren, S.G., C.J. Hahn, J. London, R.M. Chervin, and R.L. Jenne (1988). Global distribution of total cloud cover and cloud type amounts over the ocean. NCAR/ TN-317+STR, National Center for Atmospheric Research, Boulder, Colorado.

Yanes, A.V. (1962) Melting of snow and ice in the central Arctic. Problems of the Arctic and Antarctic, 11: g1-g13.

Zachek, A.S. (1996) The experimental investigation of the radiation effects of Arctic haze (in Russian). Trudy, Arkticheskogo i Antarkticheskogo Naucho-Issledovatelskogo Instituta, 434: 218-222. 
BLANK 


\section{APPENDIX A: DETAILS OF EQUATIONS 3 AND 4}

Suppose we have a series $T_{\mathrm{i}}$ of $N$ surface-layer air temperature measurements. The average temperature is

$$
\bar{T}=\frac{1}{N} \sum_{i=1}^{N} T_{\mathrm{i}},
$$

and the standard deviation is

$$
\sigma_{\mathrm{T}}=\left[\frac{1}{N-1} \sum_{i=1}^{N}\left(T_{\mathrm{i}}-\bar{T}\right)^{2}\right]^{1 / 2}
$$

Since the $T_{\mathrm{i}}$ are approximately normally distributed,

$$
\tilde{T}_{\mathrm{i}}=\frac{T_{\mathrm{i}}-\bar{T}}{\sigma_{\mathrm{T}}}
$$

is approximately normal with mean 0 and variance 1 . That is, the probability density function for $\tilde{T}$ is

$$
\phi_{1}(\tilde{T})=\frac{1}{\sqrt{2 \pi}} \exp \left(-\tilde{T}^{2} / 2\right),
$$

and the cumulative distribution function is

$$
\Phi_{1}(\tilde{T})=\int_{-\infty}^{\tilde{T}} \phi_{1}\left(T^{\prime}\right) d T^{\prime} .
$$

We have already discussed the distribution function for total cloud amount $n$; call this $\phi_{2}(n)$, where

$$
\begin{aligned}
\phi_{2}(n) & =\frac{\Gamma(\hat{\alpha}+\hat{\beta})}{\Gamma(\hat{\alpha}) \Gamma(\hat{\beta})} n^{\hat{\alpha}-1}(1-n)^{\hat{\beta}-1} & & \text { for } 0 \leq n \leq 1, \\
& =0 & & \text { otherwise. }
\end{aligned}
$$

Again, Table 4 lists appropriate $\hat{\alpha}$ and $\hat{\beta}$ values to use in winter. The cumulative distribution function for total clouds is thus

$$
\Phi_{2}(n)=\int_{0}^{n} \phi_{2}\left(n^{\prime}\right) d n^{\prime}
$$

We seek a function that predicts total cloud amount from surface-layer air temperature alone. In other words, in terms of $\tilde{T}$, we want $\psi$ such that

$$
n=\psi(\tilde{T}) .
$$

Based on Tables 1-3 and physical intuition, we can reasonably assume that $\psi(\tilde{T})$ is a monotonically increasing function of $\tilde{T}$. From mathematical statistics, we know we can then approximate (Ventcel 1964, p. 263 ff.) 


$$
\Phi_{1}(\tilde{T}) \cong \int_{0}^{\psi(\tilde{T})} \phi_{2}\left(n^{\prime}\right) d n^{\prime}=\Phi_{2}[\psi(\tilde{T})]
$$

Consequently,

$$
n=\psi(\tilde{T}) \cong \Phi_{2}^{-1}\left[\Phi_{1}(\tilde{T})\right]
$$

where $\Phi_{2}^{-1}$ is the inverse function of $\Phi_{2}(n)$.

Since $\Phi_{2}(n)$ describes a beta distribution, $\Phi_{2}^{-1}$ must be the inverse of a beta distribution. Aivazyan et al. (1983) give

$$
n(\tilde{T}) \cong \Phi_{2}^{-1}\left[\Phi_{1}(\tilde{T})\right] \cong \frac{\hat{\alpha}}{\hat{\alpha}+\hat{\beta} \exp [2 w(\tilde{T})]}
$$

where

$$
\begin{aligned}
& w(\tilde{T})=\frac{\tilde{T}|h+\lambda|^{1 / 2}}{h}-\left(\frac{1}{2 \hat{\beta}-1}-\frac{1}{2 \hat{\alpha}-1}\right)\left(\lambda+\frac{5}{6}-\frac{2}{3 h}\right), \\
& h=2\left(\frac{1}{2 \hat{\alpha}-1}+\frac{1}{2 \hat{\beta}-1}\right)^{-1}, \\
& \lambda=\frac{\tilde{T}^{2}-3}{6} .
\end{aligned}
$$



VA 22202-4302, and to the Office of Management and Budget, Paperwork Reduction Project (0704-0188), Washington, DC 20503.

\begin{tabular}{|l|l|l}
\hline 1. AGENCY USE ONLY (Leave blank) & $\begin{array}{c}\text { 2. REPORT DATE } \\
\text { December } 1998\end{array}$ & 3. REPORT TYPE AND DATES COVERED \\
\hline
\end{tabular}

4. TITLE AND SUBTITLE

December 1998

Accounting for Clouds in Sea Ice Models

6. AUTHORS

Aleksandr P. Makshtas, Edgar L Andreas, Pavel N. Svyashchennikov, and

Valery F. Timachev

7. PERFORMING ORGANIZATION NAME(S) AND ADDRESS(ES)

FUNDING NUMBERS

U.S. Army Cold Regions Research and Engineering Laboratory

72 Lyme Road

Hanover, New Hampshire 03755-1290

Contract nos.:

N0001496MP30005 (ONR)

OPP-90-24544 \& OPP-93-12642

DA Project 4A161102AT24

Russian Fund Projects:

96-07-89159 \& 97-05-65926

8. PERFORMING ORGANIZATION

REPORT NUMBER

CRREL Report 98-9

9. SPONSORING/MONITORING AGENCY NAME(S) AND ADDRESS(ES)

10. SPONSORING/MONITORING AGENCY REPORT NUMBER

U.S. Office of Naval Research, Arlington, Virginia 22217-5660

U.S. National Science Foundation, Arlington, Virginia 22230

Office of the Chief of Engineers, Washington, D.C. 20314-1000

Russian Fund for Fundamental Investigations, Moscow

11. SUPPLEMENTARY NOTES

For conversion of SI units to non-SI units of measurement, consult ASTM Standard E380-93, Standard Practice for Use of the International System of Units, published by the American Society for Testing and Materials, 100 Barr Harbor Drive., West Conshohocken, Pennsylvania 19428-2959.

12a. DISTRIBUTION/AVAILABILITY STATEMENT

12b. DISTRIBUTION CODE

Approved for public release; distribution is unlimited.

Available from NTIS, Springfield, Virginia 22161

13. ABSTRACT (Maximum 200 words)

Over sea ice in winter, the clouds, the surface-layer air temperature, and the longwave radiation are closely coupled. This report uses archived data from the Russian North Pole (NP) drifting stations and recent data from Ice Station Weddell (ISW) to investigate this coupling. Both Arctic and Antarctic distributions of total cloud amount are U-shaped: that is, observed cloud amounts are typically either 0-2 tenths or 8-10 tenths in the polar regions. These data obey beta distributions; roughly 70 station-years of observations from the NP stations yielded fitting parameters for each winter month. Although surface-layer air temperature and total cloud amount are correlated, it is not straightforward to predict one from the other, because temperature is normally distributed while cloud amount has a U-shaped distribution. Nevertheless, the report presents a statistical algorithm that can predict total cloud amount in winter from surface-layer temperature alone and, as required, produces a distribution of cloud amounts that is U-shaped. Because sea ice models usually need cloud data to estimate incoming longwave radiation, this algorithm may be useful for estimating cloud amounts and, thus, for computing the surface heat budget where no visual cloud observations are available but temperature is measured-from the Arctic buoy network or from automatic weather stations, for example. The incoming longwave radiation in sea ice models is generally highly parameterized. The report evaluates five common parameterizations using data from NP-25 and ISW. The formula for estimating incoming longwave radiation that König-Langlo and Augstein

\begin{tabular}{|c|c|c|c|c|c|}
\hline \multirow{2}{*}{$\begin{array}{l}\text { 14. SUBJECT TERMS } \\
\text { Cloud cover } \\
\text { Longwave radiation }\end{array}$} & \multirow[b]{2}{*}{$\begin{array}{l}\text { Modeling } \\
\text { Polar regions }\end{array}$} & \multirow{2}{*}{\multicolumn{2}{|c|}{$\begin{array}{l}\text { Radiation balance } \\
\text { Sea ice }\end{array}$}} & \multirow[b]{2}{*}{ Surface heat budget } & \multirow{2}{*}{$\begin{array}{l}\text { 15. NUMBER OF PAGES } \\
\frac{39}{16 . \text { PRICE CODE }}\end{array}$} \\
\hline & & & & & \\
\hline $\begin{array}{l}\text { 17. SECURITY CLASSIFICATION } \\
\text { OF REPORT }\end{array}$ & \multicolumn{2}{|c|}{$\begin{array}{l}\text { 18. SECURITY CLASSIFICATION } \\
\text { OF THIS PAGE }\end{array}$} & \multicolumn{2}{|c|}{$\begin{array}{l}\text { 19. SECURITY CLASSIFICATION } \\
\text { OF ABSTRACT }\end{array}$} & 20. LIMITATION OF ABSTRACT \\
\hline UNCLASSIFIED & \multicolumn{2}{|c|}{ UNCLASSIFIED } & \multicolumn{2}{|c|}{ UNCLASSIFIED } & UL \\
\hline
\end{tabular}


developed using both Arctic and Antarctic data has the best properties but does depend nonlinearly on total cloud amount. This nonlinearity is crucial since cloud distributions are U-shaped, while common sources of cloud data tabulate only mean monthly values. The report therefore closes by using a one-dimensional sea ice model to investigate how methods of averaging cloud amounts affect predicted sea ice thickness in the context of the five longwave radiation parameterizations. 